\title{
In vitro education of human natural killer cells by KIR3DL1
}

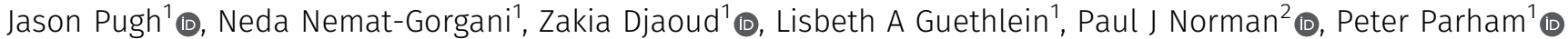

\begin{abstract}
During development, NK cells are "educated" to respond aggressively to cells with low surface expression of HLA class I, a hallmark of malignant and infected cells. The mechanism of education involves interactions between inhibitory killer immunoglobulin-like receptors (KIRs) and specific HLA epitopes, but the details of this process are unknown. Because of the genetic diversity of HLA class I genes, most people have NK cells that are incompletely educated, representing an untapped source of human immunity. We demonstrate how mature peripheral KIR3DL1 ${ }^{+}$human NK cells can be educated in vitro. To accomplish this, we trained NK cells expressing the inhibitory KIR3DL1 receptor by co-culturing them with target cells that expressed its ligand, Bw4 ${ }^{+} H L A-B$. After this training, KIR3DL1 ${ }^{+}$NK cells increased their inflammatory and lytic responses toward target cells lacking Bw4 ${ }^{+}$HLA-B, as though they had been educated in vivo. By varying the conditions of this basic protocol, we provide mechanistic and translational insights into the process NK cell education.
\end{abstract}

DOI 10.26508/lsa.201900434 | Received 20 May 2019 | Revised 1 November 2019 | Accepted 4 November 2019 | Published online 13 November 2019

\section{Introduction}

NK cells are innate immune cells that contribute to human immunity and placentation (Parham \& Moffett, 2013). Like T cells, NK cells travel throughout the body, and have the ability to lyse infected or malignant cells upon contact. Unlike T cells, however, NK cells do not require cooperation from other immune cells to mount an immune response (Greenberg \& Playfair, 1974; Kiessling et al, 1976). Despite this lack of oversight, NK cells rarely harm healthy tissue or cause autoimmunity (Toubi \& Vadasz, 2019). NK cells accurately target unhealthy cells in part because they sense proteins that are typically expressed on the surface of healthy cells. Among these proteins are the Class I HLA proteins, which are expressed by almost all healthy human cells (Boegel et al, 2018).

NK cells detect HLA on other cells using killer immunoglobulinlike receptors (KIRs) (Colonna \& Samaridis, 1995). When an inhibitory KIR on an NK cell binds to HLA on another cell, the KIR initiates an inhibitory signal that counters activation (Valiante et al, 1996; Lanier, 2003). Malignancy and infection can each reduce a cell's expression of HLA, making that cell a target for NK cells (Seliger et al, 1997; Bukur et al, 2012; Crux \& Elahi, 2017). A missing-self response occurs when an NK cell attacks another cell because that cell does not express enough HLA.

NK cells that do not express any inhibitory receptors are hyporesponsive, likely because of the absence of the activation kinases Syk and Zap70 (Pugh et al, 2018). The magnitude of the missing-self response of $\mathrm{KIR}^{+}$NK cells depends on whether their KIR bound HLA during cellular development. The binding of HLA by KIR during NK cell development is said to "educate" the NK cell to have a greater response if that specific HLA epitope is missing from cells it encounters thereafter (Kim et al, 2008). KIR NK cells that did not bind HLA during development have a comparably diminished missing-self response as a result and are called uneducated (Anfossi et al, 2006).

The KIR gene locus contains up to five inhibitory KIR genes per person (Guethlein et al, 2015). Each inhibitory KIR binds to a specific epitope on HLA (Parham \& Moffett, 2013). KIR3DL2 binds the A3/11 epitope found on some HLA-A alleles. KIR3DL1 binds the Bw4 epitope of HLA-B or HLA-A. KIR2DL2 and KIR2DL3 each bind the C1 epitope, which occurs on many HLA-C and two HLA-B alleles (Moesta et al, 2008). KIR2DL1 binds the C2 epitope of HLA-C. Other inhibitory receptors expressed by NK cells include CD94:NKG2A and LILRB1, which inhibit NK cells when bound to HLA-E (Sullivan et al, 2008). Inhibitory KIR genes are switched on stochastically during NK cell development, such that individual NK cells express different numbers and combinations of KIR (Andersson et al, 2009; Schonberg et al, 2011).

Class I HLA genes are the most diverse genes in the human population, comprising thousands of HLA-A, - B, and -C alleles (Robinson et al, 2017). The diversity of KIR genes is also high (Guethlein et al, 2015; Misra et al, 2018). As a result of this combined diversity, less than $5 \%$ of the human population has a genotype in which NK cells are educated through all possible KIR-HLA interactions (Robinson et al, 2016).

Their relative safety and their ability to recognize and lyse malignant cells make NK cells an obvious choice for the development of immunotherapies. However, many NK cell immunotherapies have thus far underperformed in the clinic (Karre et al, 1986; Storkus et al, 1987; Eguizabal et al, 2014; Gras Navarro et al, 2015). One potential reason for this is that NK cells that lack education never reach their full potential. Strategies for boosting the response of NK cells to cancer include blocking KIR-HLA binding in vivo, which theoretically promotes NK cell activation (Kim \& Kim, 2018). However, KIR blockade ${ }^{1}$ Departments of Structural Biology and Microbiology \& Immunology, Stanford University School of Medicine, Stanford, CA, USA ${ }^{2}$ Division of Biomedical Informatics and
Personalized Medicine, Department of Immunology, School of Medicine, University of Colorado Denver, Denver, CO, USA

Correspondence: peropa@stanford.edu 
interventions have thus far not been successful in clinical trials. This may be partly because they are only applicable to the degree that the patient's NK cells have been educated in vivo through the targeted KIRs. By genetic chance, most individuals lack the ability to educate all of their NK cells in vivo. In this study, for the first time to our knowledge, we provide evidence that mature human peripheral NK cells expressing KIR3DL1 can be educated in vitro.

\section{Results}

\section{General approach to in vitro NK cell education by KIR3DL1}

To explore the possibility of achieving in vitro NK cell education, we chose to study KIR3DL1 ${ }^{+}$NK cells. These cells are educated in vivo through KIR3DL1 binding to the Bw4 epitope carried by some HLA-A and $B$ allotypes. We studied donors with uneducated KIR3DL1 ${ }^{+}$NK cells, as defined by their lack of any HLA-A or HLA-B Bw4 epitope. We isolated and co-cultured donor NK cells with a target B cell line that expressed $B W 4^{+} H L A-B$. As a control, we also co-cultured their isolated NK cells with a target BCL that expressed only Bw4- HLA-A and - $\mathrm{B}$. This first co-culture is called the training phase (Fig 1). We similarly trained NK cells from BW $4^{+} \mathrm{HLA}-\mathrm{B}$ donors. After the training phase, we added K562 target cells to each co-culture to test NK cell function. K562 are erythroleukemia cells that lack HLA class I. NK cells were then assayed for IFNY production and degranulation. This second co-culture is called the testing phase (Fig 1). We expected that $3 \mathrm{DL}^{+} \mathrm{NK}$ cells from $\mathrm{Bw}^{-}$donors trained on $\mathrm{BW}^{+}$ targets would be educated in the training phase, leading to greater IFNy production and degranulation in the testing phase. We also anticipated that NK cells from many Bw4 $4^{+}$donors trained on $\mathrm{Bw}^{+}$ targets would have increased IFNy production in the testing phase

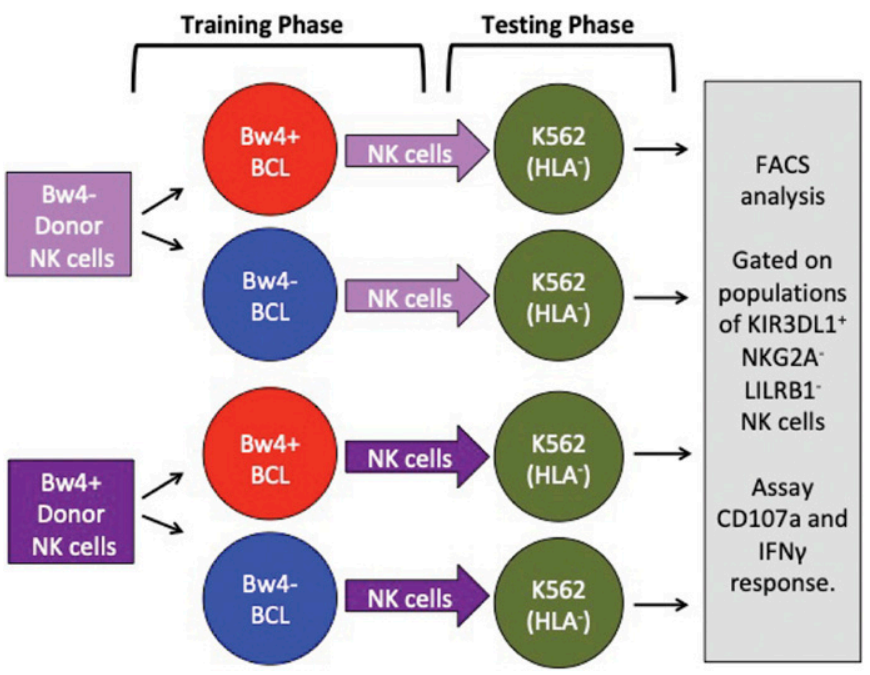

Figure 1. General approach to in vitro NK cell education.

In the training phase (left), NK cells isolated from either $\mathrm{BW}^{+}$or $\mathrm{BW}_{4}^{-}$donors are co-cultured with training cells that express either BW $4^{+} \mathrm{HLA}-\mathrm{B}$ (educating) or Bw $4^{-}$HLA-B (control). Testing lines are pretreated with etoposide VP-16. In the testing phase (right), K562 cells, which lack HLA class I, are added. The missingself response of $\mathrm{KIR} \mathrm{DL} 1^{+} \mathrm{NK}$ cells to the $\mathrm{HLA}^{-}$targets is then measured by IFNY and/or degranulation assays using flow cytometry. because the Bw $4^{+} \mathrm{HLA}-\mathrm{B}$ allotypes expressed by the training cell lines have higher avidity for KIR3DL1 than most allotypes expressed by our cohort of NK cell donors.

In vivo education by KIR3DL1 is detectable by IFNy production, but not degranulation, after extended cell culture with recombinant human IL-2

We first tested the robustness of in vivo NK cell education using samples from our donor cohort and conditions similar to those planned for in vitro NK cell education, notably a 5-d cell culture with IL-2. Two concentrations of recombinant human IL-2 were compared: low $100 \mathrm{U} / \mathrm{ml}$ and high $500 \mathrm{U} / \mathrm{ml} \mathrm{IL-2}$. After the culture, NK cells were tested for a missing-self response against K562 target cells. IFNy production and NK cell degranulation were assayed by flow cytometry. We compared the response of KIR3DL1 ${ }^{+} \mathrm{NK}$ cells from $\mathrm{Bw}^{+}$donors, which were educated in vivo by Bw4, to KIR3DL1 ${ }^{+}$ NK cells from Bw4- donors, which were not educated by Bw4. To reduce effects due to inhibitory receptors other than KIR, NK cells expressing NKG2A and/or LILRB1 were excluded from the analysis.

After culture in high IL-2, KIR3DL1 ${ }^{+} \mathrm{NK}$ cells from Bw4 $4^{+}$donors produced more IFNy in response to missing-self than KIR3DL1 ${ }^{+} \mathrm{NK}$ cells from Bw4- donors (Fig 2A). On average, in vivo education by Bw4 accounted for a $47 \%$ increase in the frequency of KIR3DL1 ${ }^{+} \mathrm{NK}$ cells producing IFNY (formula in the Materials and Methods section). Although in vivo education by Bw4 increased the IFNy response, it had no effect on CD107a expression, a proxy for degranulation. This negative result was observed for NK cells cultured in high or low IL-2 (Fig 2B).

In these experiments, in vivo education mediated by KIR3DL1 was observed for the cytokine response but not the cytotoxic response. Thus, any effect of in vivo NK cell education mediated by KIR3DL1 on the cytotoxic response is no longer apparent after a 5- $d$ cell culture with IL-2.

\section{$\mathrm{KIR} \mathrm{DL1} 1^{+} \mathrm{NK}$ cells from Bw4 ${ }^{-}$donors exhibit increased missing- self response after in vitro education with a $\mathrm{Bw} 4^{+} \mathrm{BCL}$}

To educate KIR3DL1 ${ }^{+} \mathrm{NK}$ cells in vitro, NK cells isolated from BW4 $4^{+}$to $B 4^{-}$donors were co-cultured with one of two EB- transformed $B$ cell lines $(\underline{B C L})$, either a $B w 4^{+} \mathrm{BCL}$ or a $\mathrm{Bw} 4^{-} \mathrm{BCL}$. Both $\mathrm{BCL}$ express similar amounts of cell surface HLA class I (Fig S1A). Training Cocultures were performed in either low or high IL-2 conditions. After $5 \mathrm{~d}$ of co-culture, NK cells were tested for a missing-self response against K562 target cells in high IL-2 medium. IFNy production and degranulation were assayed by flow cytometry. NK cells expressing NKG2A and/or LILRB1 were excluded from analysis.

For NK cells cultured in low IL-2, KIR3DL1 $1^{+} \mathrm{NK}$ cells from BW4donors gained a significant increase in their IFNY response to missing-self when trained with $\mathrm{Bw} 4^{+} \mathrm{BCL}$, compared with training with $\mathrm{Bw} 4^{-} \mathrm{BCL}$ (Fig $3 \mathrm{~A}$ ). On combining data from three experiments representing $25 \mathrm{Bw}^{-}$donors, in vitro education by $\mathrm{Bw} 4^{+} \mathrm{BCL}$ in low IL-2 accounted for a $38 \%$ increase in the frequency of IFNY ${ }^{+}$cells (Table 1). In a combined analysis of $20 \mathrm{Bw}^{+}$donors, in vitro education by $B w 4^{+} \mathrm{BCL}$ in low IL-2 accounted for a $68 \%$ increase in the frequency of IFNy ${ }^{+}$cells (Table 1). However, the effect of in vitro education in low IL-2 on NK cells from $\mathrm{BW}^{+}$donors did not reach 


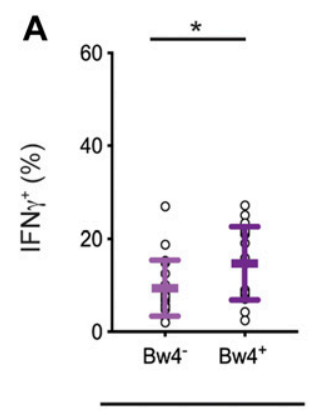

$100 \mathrm{U} / \mathrm{ml} \mathrm{rhlL}-2$

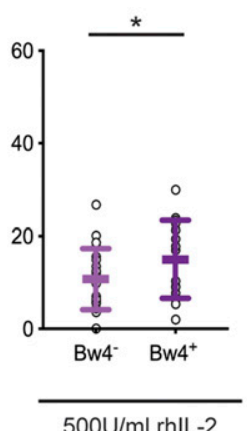

$500 \mathrm{U} / \mathrm{ml} \mathrm{rhlL}-2$

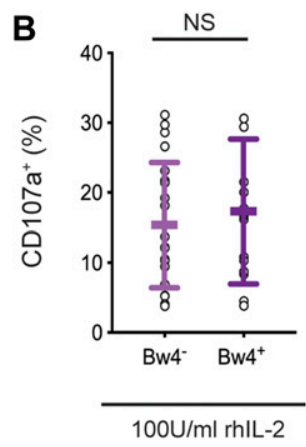

$100 \mathrm{U} / \mathrm{ml} \mathrm{rhlL}-2$

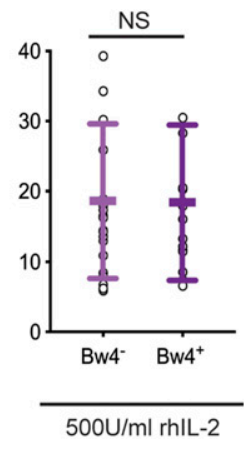

Figure 2. After $\mathbf{5} \mathrm{d}$ of in vitro cell culture, NK cell education is detectable by IFN $\gamma$ production but not degranulation.

NK cells isolated from PBMCs were cultured in medium with rhIL-2 at the concentrations indicated. After $5 \mathrm{~d}$, the $\mathrm{K} 562$ cells were added at a 10:1 E:T ratio, in medium with $500 \mathrm{U} / \mathrm{ml}$ rhIL-2 and anti-CD107a. $6 \mathrm{~h}$ later, the NK cells were stained and analyzed by flow cytometry. Shown are the mean \pm SD of three experiments combined totaling $21 \mathrm{Bw}^{-}$donors and $18 \mathrm{Bw}^{+}$donors. (A) Frequency of IFNy ${ }^{+}$cells in the viable KIR3DL1 ${ }^{+} N K G 2 A^{-}$LILRB1 $^{-}$NK cell gate. Shown are the results of a $t$ test. ${ }^{*} P<0.05$. (B) Frequency of $C D 107 a^{+}$cells in the viable KIR3DL1 ${ }^{+} N K G 2 A^{-}$LILRB1 $^{-}$NK cell gate. Shown are the results of a $t$ test. NS = not significant. Source data are available for this figure. statistical significance unless data from multiple experiments were combined (compare Fig 3A with Table 1).

Among NK cells cultured in high IL-2, KIR3DL1 ${ }^{+}$NK cells from Bw4donors gained a significant increase in their IFNy response to missingself when trained with $\mathrm{BW} 4^{+} \mathrm{BCL}$, compared with training with $\mathrm{BW} 4^{-} \mathrm{BCL}$ (Fig 3A). Training with $B W 4^{+} \mathrm{BCL}$ in high IL-2 resulted in a $33 \%$ increase in the frequency of IFNy ${ }^{+}$cells (Table 1). In vitro education by $\mathrm{Bw} 4^{+} \mathrm{BCL}$ in high IL-2 accounted for an $85 \%$ increase in the frequency of $\mathrm{FNNY}^{+}$ cells among $20 \mathrm{Bw} 4^{+}$donors (Table 1). However, the effect of $\mathrm{Bw} 4^{+} \mathrm{BCL}$ training on NK cells from Bw $4^{+}$donors was statistically less significant than comparable training of NK cells from $\mathrm{Bw}^{-}$donors (Fig $3 \mathrm{~A}$ and Table 1).

Training with $\mathrm{BW} 4^{+} \mathrm{BCL}$ in high or low IL-2 did not affect the frequency of $\mathrm{CD} 107 \mathrm{a}^{+}$cells for either $\mathrm{Bw} 4^{+}$donors or $\mathrm{Bw} 4^{-}$donors (Fig 3B and Table 1). Because no in vivo NK cell education was detectable by degranulation after similar culture conditions (Fig $2 \mathrm{~B}$ ), this result is consistent with KIR3DL1+ cells having achieved in vitro NK cell education.

\section{$\mathrm{KIR} \mathrm{DL} 1^{+} \mathrm{NK}$ cells trained with $\mathrm{Bw} 4^{+} \mathrm{BCL}$ and rhIL-12 exhibit enhanced degranulation in response to missing-self}

To assess the effect of inflammatory cytokines on in vitro education, we trained NK cells with either $\mathrm{Bw} 4^{+} \mathrm{BCL}$ or $\mathrm{Bw} 4^{-} \mathrm{BCL}$ in medium containing both high IL-2 and $50 \mathrm{ng} / \mathrm{ml}$ recombinant human IL-12, abbreviated as IL-12. Culturing NK cells in IL-12 dramatically increased the frequency of IFNY ${ }^{+} \mathrm{NK}$ cells that responded to missing-self, resulting in $>60 \%$ of the KIR3DL1 ${ }^{+} \mathrm{NK}$ cells producing IFNy (compare Fig $3 \mathrm{~A}$ with Fig $4 \mathrm{~A}$ ). However, training with $\mathrm{Bw} 4^{+} \mathrm{BCL}$ and IL-12 did not increase the frequency of IFN ${ }^{+}$cells over that obtained from training with $B W 4^{-} B C L$ and IL-12. A similar negative result was observed for NK cells from Bw4- to Bw4 $4^{+}$donors (Fig 4A).

We next compared the degranulation of IL-12-trained KIR3DL1 ${ }^{+}$ NK cells in response to K562 cells. Among Bw4 ${ }^{-}$donors, the frequency of $\mathrm{CD}_{107 \mathrm{a}^{+}}$cells increased by $22 \%$ when trained with $\mathrm{Bw} 4^{+} \mathrm{BCL}$ and IL-12, compared with training with $\mathrm{Bw} 4^{-} \mathrm{BCL}$ and IL-12 (Fig 4B). Training KIR3DL1 $1^{+} \mathrm{NK}$ cells from Bw4 $4^{+}$donors with $\mathrm{BW} 4^{+} \mathrm{BCL}$ and IL-12 did not improve their degranulation (Fig 4B).

Next, we measured the frequency of NK cells that produced both IFNy and degranulated. KIR3DL1 ${ }^{+} \mathrm{NK}$ cells that were trained with

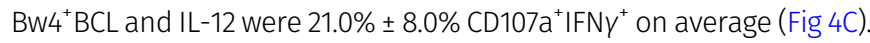
This was significantly greater than that achieved by KIR3DL1 ${ }^{+} \mathrm{NK}$ cells trained with $\mathrm{Bw} 4^{-} \mathrm{BCL}$, of which only $16.1 \% \pm 8.0 \%$ were $\mathrm{CD} 107 \mathrm{a}^{+} \mathrm{IFNY}{ }^{+}$ (Fig 4C). A statistically more significant difference was observed between $\mathrm{KIR3DL} 1^{+} \mathrm{NK}$ cells trained with $\mathrm{Bw} 4^{-} \mathrm{BCL}$ and $\mathrm{BW} 4^{+} \mathrm{BCL}$, when both degranulation and IFNY production were considered (compare Fig 4B to Fig 4C).

In summary, exposing NK cells to IL-12 overrides the effect of in vitro education on IFNy production. However, IL-12 preserves the effect of in vitro education on degranulation, which was unaffected by training with IL-2 alone. Moreover, because almost all IFNy ${ }^{+} \mathrm{NK}^{-}$ cells also degranulated in response to missing-self when trained
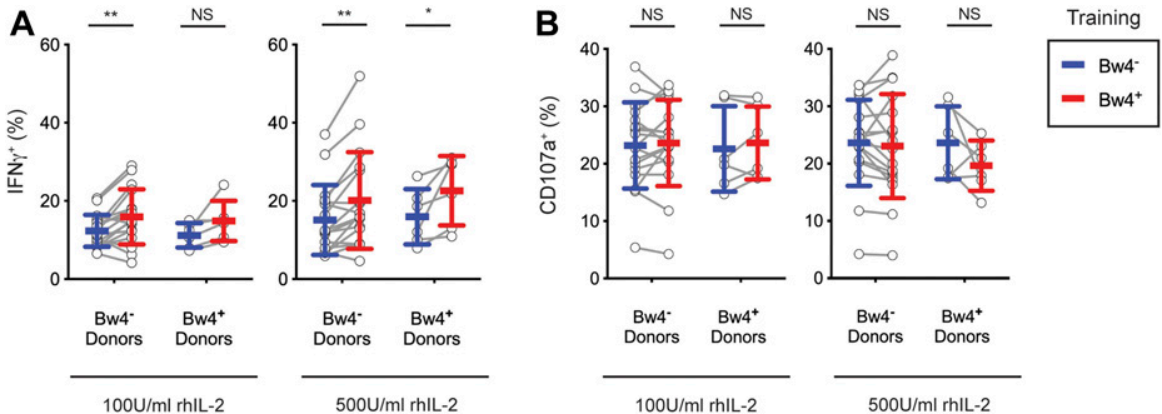
paired two-way ANOVAs. ${ }^{* *} P<0.01,{ }^{*} P<0.05$. (B) Frequency of CD107a ${ }^{+}$cells in the viable KIR3DL1 ${ }^{+}$NKG2A LILRB1 $^{-}$NK cell gate. Shown are the results of a Sidak's multiple comparison test from a paired two-way ANOVA. NS = not significant.

Source data are available for this figure.

Figure 3. In vitro training of KIR3DL1 ${ }^{+}$cells with Bw4 ${ }^{+} \mathrm{BCL}$ improves the missing-self response by IFN $\gamma$ production but not degranulation.

NK cells were isolated from the PBMCs of $17 \mathrm{BW}^{-}$donors and six BW $4^{+}$donors. NK cells were then co-cultured with either $\mathrm{Bw} 4^{+} \mathrm{BCL}$ or $\mathrm{BW} 4^{-} \mathrm{BCL}$ at an 8:3 $\mathrm{E}: \mathrm{T}$ ratio in medium with rhIL-2 at the concentrations indicated. After $5 \mathrm{~d}$, K562 cells were added at a 10:1 E:T ratio, in medium with $500 \mathrm{U} / \mathrm{ml}$ rhIL-2 and anti-CD107a. $6 \mathrm{~h}$ later, NK cells were stained and analyzed by flow cytometry. All panels are representative of at least three replicate experiments. Mean \pm SD are shown. (A) Frequency of $\mathrm{FNy}^{+}$cells in the viable KIR3DL1 $1^{+} N K G 2 A^{-}$LILRB1 $^{-}$NK cell gate. Shown are the results of a Sidak's multiple comparison test from 
Table 1. Results of in vitro training with Bw4 on the missing-self response of KIR3DL1+ $\mathrm{NK}$ cells.

\begin{tabular}{|c|c|c|c|c|c|c|c|c|c|c|c|c|c|}
\hline \multirow{2}{*}{\multicolumn{2}{|c|}{$\begin{array}{l}\text { Donor Allotype } \\
\text { Training Cell } \\
\text { Allotype }\end{array}$}} & \multicolumn{4}{|c|}{$\mathrm{Bw4}^{-}$} & \multirow{3}{*}{$\begin{array}{c}\text { \% Change } \\
\text { (IFNy) }\end{array}$} & \multirow{3}{*}{$\begin{array}{l}\text { \% Change } \\
\text { (CD107a) }\end{array}$} & \multicolumn{4}{|c|}{$B w 4^{+}$} & \multirow{3}{*}{$\begin{array}{c}\text { \% Change } \\
\text { (IFNy) }\end{array}$} & \multirow{3}{*}{$\begin{array}{l}\text { \% Change } \\
\text { (CD107a) }\end{array}$} \\
\hline & & \multicolumn{2}{|c|}{$\mathrm{BW}^{-}$} & \multicolumn{2}{|c|}{$\mathrm{Bw}^{+}$} & & & \multicolumn{2}{|c|}{$B w 4^{-}$} & \multicolumn{2}{|c|}{$\mathrm{Bw}^{+}$} & & \\
\hline \multicolumn{2}{|c|}{$\begin{array}{l}\text { Type of Response to } \\
\text { K562 }\end{array}$} & $\begin{array}{r}\text { IFNy } y^{+} \\
(\%)\end{array}$ & $\begin{array}{c}\text { CD107a }^{+} \\
(\%)\end{array}$ & $\begin{array}{r}\mathrm{IFNy} \gamma^{+} \\
(\%)\end{array}$ & $\begin{array}{c}{\mathrm{CD} 107 \mathrm{a}^{+}}(\%)\end{array}$ & & & $\begin{array}{l}\mathrm{IFNy}^{+} \\
(\%)\end{array}$ & $\begin{array}{c}{\mathrm{CD} 107 \mathrm{a}^{+}}_{(\%)}\end{array}$ & $\begin{array}{r}\mathrm{IFNy}^{+} \\
(\%)\end{array}$ & $\begin{array}{c}{\mathrm{CD} 107 \mathrm{a}^{+}}^{(\%)}\end{array}$ & & \\
\hline \multirow{2}{*}{$\begin{array}{l}\text { Training } \\
\text { conditions }\end{array}$} & $\begin{array}{l}\text { Low } \\
\text { IL2 }\end{array}$ & 10.5 & 22.4 & 14.5 & 22.9 & $38.1^{\star *}$ & 2.2 & 6.9 & 20.7 & 11.6 & 19.1 & $68.1^{* *}$ & -7.7 \\
\hline & $\begin{array}{l}\text { High } \\
\text { IL2 }\end{array}$ & 14.8 & 19.8 & 19.7 & 18.7 & $33.1^{\star *}$ & -5.6 & 11.9 & 15.9 & 22.0 & 14.8 & $84.8^{*}$ & -6.9 \\
\hline
\end{tabular}

NK cells were co-cultured with either Bw4 $4^{+} \mathrm{BCL}$ or Bw4-BCL in medium with either $100 \mathrm{U} / \mathrm{ml}$ rhIL-2 or $500 \mathrm{U} / \mathrm{ml}$ rhIL-2. After $5 \mathrm{~d}$, K562 cells were added at a 10:1 E:T ratio, in medium with $500 \mathrm{U} / \mathrm{ml}$ rhIL-2 and anti-CD107a. $6 \mathrm{~h}$ later, the NK cells were stained and analyzed by flow cytometry. Combined data from three

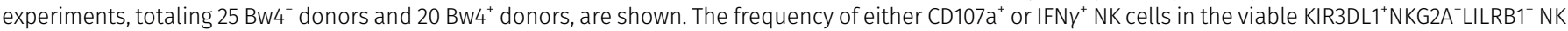

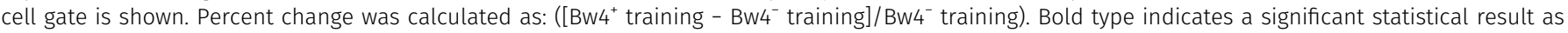
assessed by Sidak's multiple comparison test from paired two-way ANOVAs. Asterisks denote the degree of significance: ${ }^{\star \star} P<0.01,{ }^{\star} P<0.05$.

with IL-12, in vitro education with IL-12 maximizes the overall missing-self response of KIR3DL1 ${ }^{+}$NK cells.

\section{Bw4 ${ }^{+} \mathrm{BCL}$ training does not cause differences in the division, survival, or activation of NK cells that can explain their increased response to missing-self}

We next considered scenarios other than education that could explain the increased response to missing-self observed for NK cells after $B W 4^{+} \mathrm{BCL}$ training. Because NK cells were cultured with training cells for days before assessment of their missing-self response, one such scenario would be if more KIR3DL1 ${ }^{+}$NK cells survived co-culture with $\mathrm{Bw} 4^{+} \mathrm{BCL}$ cells than co-culture with $\mathrm{Bw} 4^{-} \mathrm{BCL}$ cells. To assess this possibility, the viability and KIR3DL1 expression of NK cells after $5 \mathrm{~d}$ of training were assessed. The frequency of viable KIR3DL1+ NK cells after co-culture with $\mathrm{BW}^{+} \mathrm{BCL}$ cells was not significantly greater than those of KIR3DL1 ${ }^{+}$NK cells co-cultured with Bw4- BCL cells (Fig S1C). The frequency of NK cells that divided during co-culture, as measured by bromodeoxyuridine incorporation, was no higher for NK cells trained with $\mathrm{Bw} 4^{+} \mathrm{BCL}$ than for those trained with $\mathrm{Bw} 4^{-} \mathrm{BCL}$ (Fig S1D).

Another scenario that could yield false evidence for in vitro education would be if $\mathrm{BW} 4^{+} \mathrm{BCL}$ expressed more ligands for NK cell activation than $B w 4^{-} \mathrm{BCL}$. If this was the case, NK cells lacking KIR3DL1 should also show an increased missing-self response after
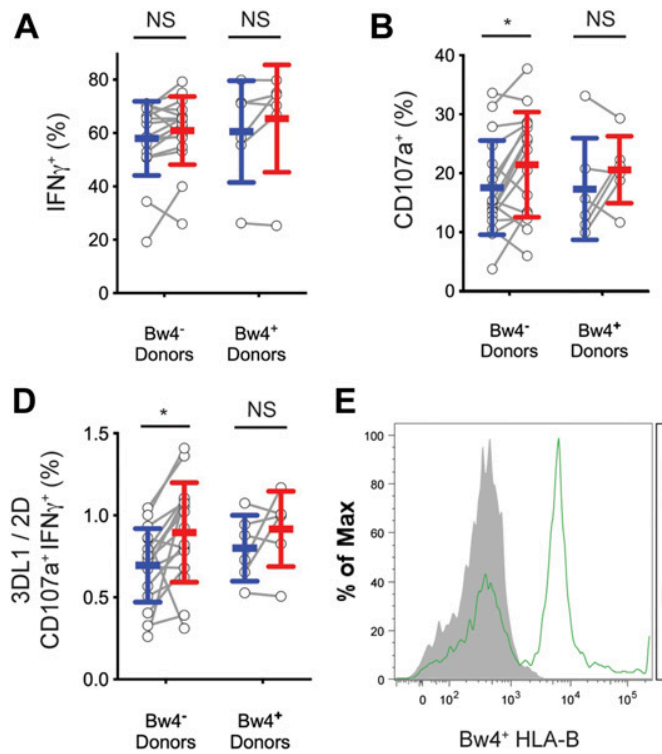

E

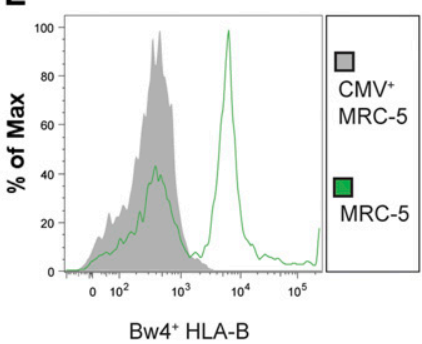

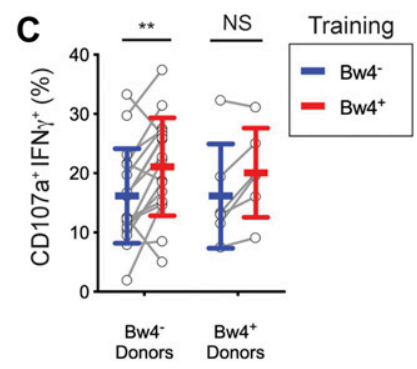

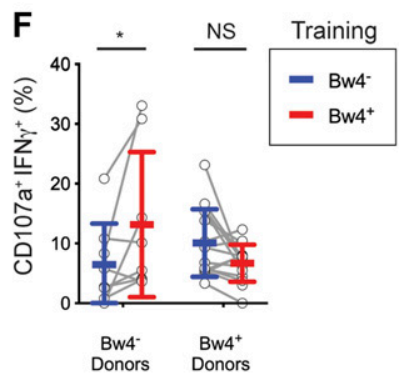

Figure 4. In vitro training with $\mathrm{Bw} 4^{+} \mathrm{BCL}$ and rhIL-12 maximizes the missing-self response of KIR3DL1 ${ }^{+}$ NK cells.

For $(A, B, C, D)$, NK cells were isolated from the PBMCs of $17 \mathrm{BW}^{-}$donors and six BW4 $4^{+}$donors. NK cells were then co-cultured with either $\mathrm{Bw} 4^{+} \mathrm{BCL}$ or $\mathrm{Bw} 4^{-} \mathrm{BCL}$ at an 8:3 E:T ratio in medium with $500 \mathrm{U} / \mathrm{ml}$ rhIL-2 and $50 \mathrm{ng} /$ $\mathrm{ml}$ rhIL-12. After 5 d, K562 cells were added at a 10:1 E: T ratio, in medium with $500 \mathrm{U} / \mathrm{ml}$ rhIL-2 and antiCD107a. $6 \mathrm{~h}$ later, NK cells were stained and analyzed by flow cytometry. (A, B, C, D) are representative of at least three replicate experiments. Mean \pm SD are shown. (A) Frequency of IFNY cells in the viable KIR3DL1 ${ }^{+}$NKG2A- ${ }^{-}$ILRB1 ${ }^{-}$NK cell gate. Shown are the results of a Sidak's multiple comparison test from a paired two-way ANOVA. (B) Frequency of CD107a ${ }^{+}$cells in the viable KIR3DL1+NKG2A- LILRB1 $^{-}$NK cell gate. Shown are the results of a Sidak's multiple comparison test from a paired two-way ANOVA. ${ }^{*} P<0.05$.

(C) Frequency of IFNY ${ }^{+} \mathrm{CD} 107 \mathrm{a}^{+}$cells in the viable KIR3DL1+NKG2A- LILRB1- NK cell gate. Shown are the results of a Sidak's multiple comparison test from a paired two-way ANOVA. ${ }^{* *} P<0.01$. (D) Frequency of IFNY ${ }^{+} \mathrm{CD} 107 a^{+}$cells in the viable KIR3DL1 ${ }^{+} \mathrm{NKG}^{-} \mathrm{A}^{-} \mathrm{LILRB1}^{-}$ NK cell gate divided by the frequency of $I F N{ }^{+} \mathrm{CD} 107 \mathrm{a}^{+}$ cells in the viable KIR3DL1 ${ }^{-}$KIR2D ${ }^{+}$NKG2A ${ }^{-}$LILRB1 $^{-} \mathrm{NK}$

cell gate. Shown are the results of a Sidak's multiple comparison test from a paired two-way ANOVA. ${ }^{*} P<0.05$. (E) MRC-5 cells were either co-cultured alone or with human CMV for $4 \mathrm{~d}$. MRC-5 cells were then isolated and stained with anti-Bw4+HLA-B antibody and analyzed by flow cytometry. Viable MRC-5 cells are shown. (F) NK cells isolated from PBMCs were co-cultured with either Bw4 $4^{+} \mathrm{BCL}$ or Bw4- $\mathrm{BCL}$ at an 8:3 E:T ratio. After $5 \mathrm{~d}$, CMV-infected MRC-5 cells were added at a 10:1 E:T ratio. $6 \mathrm{~h}$ later, the NK cells were stained and analyzed by flow cytometry. Shown are the combined results of two experiments, representing three replicate experiments. The frequency of IFNY ${ }^{+} \mathrm{CD} 107 \mathrm{a}^{+}$cells in the viable KIR3DL1 ${ }^{+} N K G 2 A^{-}$LILRB1 ${ }^{-}$NK cell gate are shown. Shown are the results of a Sidak's multiple comparison test from a paired two-way ANOVA. NS = not significant. ${ }^{*} P<0.05$.

Source data are available for this figure. 
training with $B w 4^{+} \mathrm{BCL}$. To test this possibility, we normalized the missing-self response of KIR3DL1 ${ }^{+}$NK cells to that of pan-KIR2D ${ }^{+} \mathrm{KIR}^{\mathrm{R}} \mathrm{DL} 1^{-}$ NK cells. These cells express at least one KIR and have, therefore, reached a similar stage of maturity as KIR3DL1 ${ }^{+}$cells, but are unaffected by interactions with $B W 4^{+} H L A-B$. Among NK cells trained with $B w 4^{+} B C L$, the $3 D L 1 /$ pan-2D ratio of $C D 107 a^{+} I F N \gamma^{+} N K$ cells responding to missing-self was $0.90 \pm 0.30$, a significantly higher ratio than the $0.70 \% \pm 0.22 \%$ gained by $B w 4^{-} \mathrm{BCL}$ training (Fig $4 \mathrm{D}$ ). This result confirms that the improvement conferred by $\mathrm{Bw} 4^{+} \mathrm{BCL}$ training is specific to KIR3DL1 ${ }^{+} \mathrm{NK}$ cells. Therefore, the increased response to missing-self that we observed in NK cells after Bw $4^{+} \mathrm{BCL}$ training was not due to an abundance of NK cell activation ligands on the $B w 4^{+} \mathrm{BCL}$ compared with the Bw4 ${ }^{-} \mathrm{BCL}$.

\section{After training with Bw4 ${ }^{+} \mathrm{BCL}, \mathrm{KIR} \mathrm{DL} 1^{+} \mathrm{NK}$ cells from Bw4 ${ }^{-}$ individuals respond better to missing-self induced by CMV infection}

We next tested if training KIR3DL1 ${ }^{+} \mathrm{NK}$ cells with a $\mathrm{BW} 4^{+} \mathrm{BCL}$ could enhance their response to target cells that had lost HLA expression due to a viral infection. We chose the human fibroblast line MRC-5 as a viral host because one of its HLA-B allotypes has the Bw4 epitope (Tabi et al, 2001). We infected MRC-5 cells with human CMV because CMV uses immunoevasins (Babic et al, 2010) to downregulate HLA-A and HLA-B from the surface of MRC-5 cells (Ameres et al, 2013). We, therefore, predicted that KIR3DL1+ NK cells educated with Bw4 should respond more aggressively to CMV-infected MRC-5 cells than KIR3DL1+ NK cells lacking education with Bw4.

After infection with CMV, MRC-5 cells down-regulated their surface expression of HLA-B, as measured by an antibody targeting the Bw4 epitope of HLA-B (Fig 4E). Among KIR3DL1 ${ }^{+}$NK cells from Bw $4^{-}$donors, $13.2 \% \pm 12.1 \%$ of those trained with the $\mathrm{BW} 4^{+} \mathrm{BCL}$ responded to $C M V$-infected $M R C-5$ cells by degranulation and production of IFNY (Fig 4F). This was significantly more cells than the $6.5 \% \pm 6.9 \%$ degranulation and IFNy production achieved by KIR3DL1 ${ }^{+} \mathrm{NK}$ cells trained with the Bw4 ${ }^{-} \mathrm{BCL}$. KIR3DL1 ${ }^{+} \mathrm{NK}$ cells from $B 4^{+}$donors showed no improvement in their responses to CMVinfected MRC- 5 cells because of training with $B W 4^{+} B C L$ (Fig 4F). We conclude that in vitro education through $\mathrm{KIR} 3 \mathrm{DL} 1^{+}$improves the response to missing-self, induced by CMV infection.

\section{In vitro education of KIR3DL1 ${ }^{+}$NK cells by Bw4 ${ }^{+} H L A-B$ depends on the interaction of KIR3DL1 with Bw4 ${ }^{+}$HLA-B}

The NK cells of some donors showed no improvement after training with $\mathrm{Bw} 4^{+} \mathrm{BCL}$ (Fig 4C). NK cell education depends upon the strength of the interaction between KIR3DL1 and HLA-B, which varies with both the KIR3DL1 and HLA-B allotypes (Carr et al, 2005; Yawata et al, 2006; Boudreau et al, 2016). Thus, donor variation in KIR3DL1 and/or allotype could explain these differences in the efficacy of training. To examine this possibility, we calculated a relative binding and expression factor (B\&EF) using the KIR3DL1 and HLA-B types of the donors as well as the HLA-B types of the $B w 4^{+} B C L$ (see the Materials and Methods section). The $B \& E F$ value reflects the strength of the KIR3DL1-Bw4 interaction during training, as well as the average surface expression of KIR3DL1 for each donor. The increased response to missing-self due to $\mathrm{Bw} 4^{+} \mathrm{BCL}$ training was then calculated as the difference in the frequency of $\mathrm{CD} 107 \mathrm{a}^{+} \mathrm{IFN \gamma ^{+ }}$ NK cells after training with $\mathrm{Bw} 4^{+} \mathrm{BCL}$ or $\mathrm{Bw} 4^{-} \mathrm{BCL}$ (data shown in Fig $4 \mathrm{C}$ ).

A higher B\&EF was positively correlated with greater increase in the missing-self response due to in vitro education (Fig 5A). This correlation was significant $(P<0.004)$ and had an $r^{2}$ of 0.54 . This result suggests that the number and strength of the bonds between KIR3DL1 on NK cells and HLA-B on the BW $4^{+} \mathrm{BCL}$ determines the efficacy of in vitro education.

We further tested whether the improved missing-self response caused by BW $4^{+} \mathrm{BCL}$ training depended on the binding of KIR3DL1 to the $B w 4^{+} H L A-B$ present in the training phase. To do this, we compared in vitro education by $\mathrm{Bw} 4^{+} \mathrm{BCL}$ in the presence and absence of $F\left(a b^{\prime}\right)_{2}$ fragments derived from W6/32, an HLA class I-specific monoclonal antibody (Fig S2A). In the presence of W6/32 $\mathrm{F}\left(\mathrm{ab} \mathrm{b}_{2}\right)_{2}$ there was no significant missing-self response that resulted from culture with either $\mathrm{BW} 4^{+} \mathrm{BCL}$ or $\mathrm{BW} 4^{-} \mathrm{BCL}$ (Fig 5B). In contrast, in the absence of $W 6 / 32 \mathrm{~F}\left(\mathrm{ab}^{\prime}\right)_{2}$, Bw $4^{+} \mathrm{BCL}$ training led to a significantly higher missing-self response than $\mathrm{Bw} 4^{-} \mathrm{BCL}$ training (Fig 5B).

These results show that the binding of KIR3DL1 expressed on NK cells to $B w 4^{+} H L A-B$ expressed on $B C L$ cells during the training phase is responsible for the enhanced missing-self response we observed among KIR3DL1+ NK cells.

\section{In vitro education of KIR3DL1 ${ }^{+}$NK cells by a B cell line expressing Bw4 ${ }^{+}$HLA-B}

We tested if in vitro NK cell education could be achieved by a single Bw $4^{+} H L A-B$ allotype. To do this, the 721.221 cell line, which has no endogenous expression of HLA class I, was transfected to express HLA- $B^{\star} 58: 01$ that has the Bw4 epitope $\left(221 \mathrm{Bw} 4^{+}\right)$. As well as this 221Bw $4^{+}$transfectant, a control transfectant $\left(221 \mathrm{Bw} 4^{-}\right)$was made that expresses $H L A-B^{\star} 08: 01$ and lacks the Bw4 epitope. The HLA$B^{\star}$ 08:01 and $H L A-B{ }^{*} 58: 01$ constructs used for transfection were mutated at critical positions to ensure that the nonamer peptides derived from the leader sequence could not be bound by HLA-E (Michaelsson et al, 2002).

After training by the 221Bw $4^{+}$transfectant, $\mathrm{KIR} 3 \mathrm{DL} 1^{+} \mathrm{NK}$ cells from Bw $4^{-}$donors exhibited a greater missing-self response than that achieved by training KIR3DL1 ${ }^{+} \mathrm{NK}$ cells with the $221 \mathrm{~B} w 4^{-}$transfectant (Fig 5C). That such education was achieved alone by Bw $4^{+} \mathrm{HLA}-\mathrm{B}$ suggests that in vitro education of ${\mathrm{KIR} 3 D L 1^{+}}^{+} \mathrm{NK}$ cells is not dependent on any inhibitory receptor other than KIR3DL1.

In preliminary experiments, we found that if 721.221 training cells were not treated with VP-16 etoposide before education, viable $\mathrm{BW}^{+}$training cells remained present during the testing phase, where they inhibited the response of KIR3DL1 ${ }^{+}$NK cells to K562 target cells (Fig S2C). Subsequently, we ensured that all the training cells had been killed before beginning the effector phase.

\section{In vitro education of KIR3DL1 ${ }^{+} \mathrm{NK}$ cells requires training by the intact Bw4 epitope}

We next investigated whether an intact Bw4 epitope was required to educate KIR3DL1 ${ }^{+}$NK cells in vitro. Previous analysis (Sanjanwala et al, 2008) showed that replacement of leucine 82 with arginine (mutant L82R) abrogated the Bw4 epitope of HLA-B*51:01, whereas replacement of isoleucine 80 with asparagine (mutant I80N) mutant 


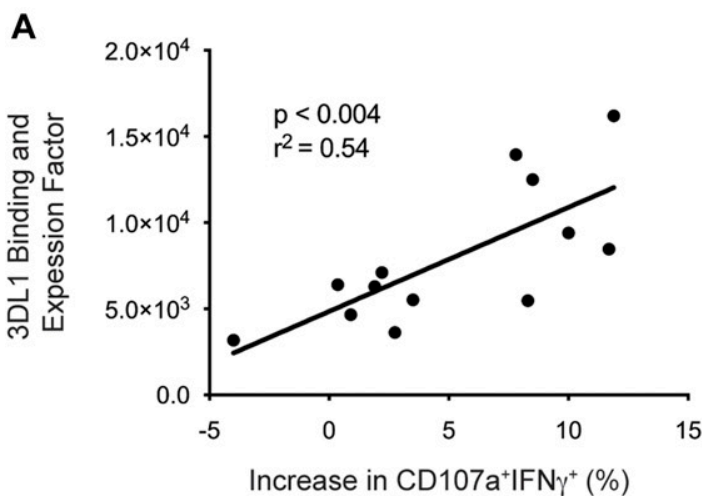

C

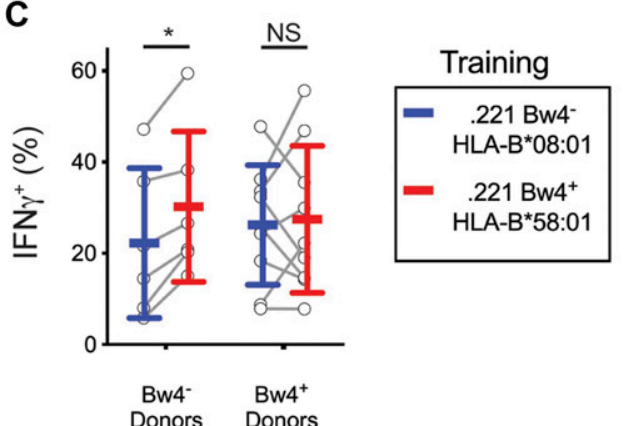

B
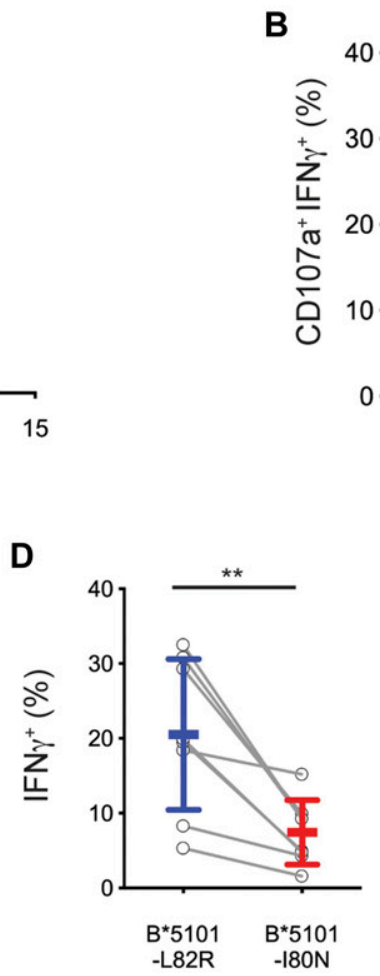

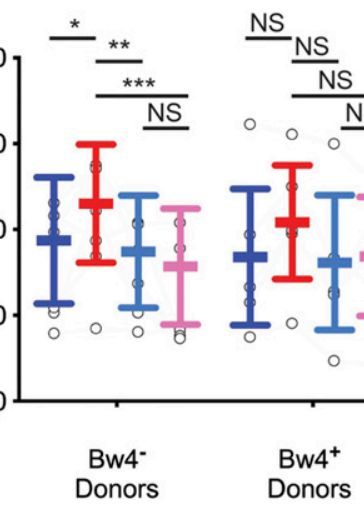

Training

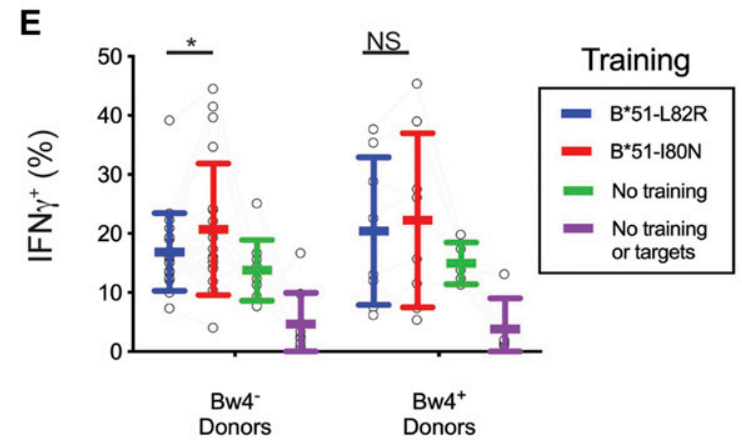

Figure 5. The increased missing-self response of NK cells trained with $B w 4^{+} \mathrm{BCL}$ is dependent on the binding of KIR3DL1 to HLA.

(A) Y-axis: AB\&EF was assigned to each of 13 donors based on published KIR3DL1-HLA-B binding data (Boudreau et al, 2016), the HLA-B genotypes of BW4 ${ }^{+} B C L$, and the surface KIR3DL1 expression for each donor's NK cells as measured by mean fluorescence intensity (MFI). X-axis: Difference between Bw4 ${ }^{+} B C L$ and Bw4- $B C L$ training in the frequency of IFNY ${ }^{+} \mathrm{CD} 107 \mathrm{a}^{+}$cells responding to missing-self, as presented in Fig 4D. Shown is the linear regression with the significance of non-zero slope and the goodness of fit calculation. These data are representative of at least three replicate experiments. (B) Bw4 ${ }^{+} \mathrm{BCL}$ and $\mathrm{Bw} 4^{-} \mathrm{BCL}$ were treated with $\mathrm{F}\left(\mathrm{ab} \mathrm{b}^{\prime}\right)_{2}$, fragments of the anti-HLA antibody W6/32. NK cells were isolated from PBMCs and co-cultured with either treated or untreated Bw4 ${ }^{+} \mathrm{BCL}$ or Bw4-BCL. Cells were co-cultured at an 8:3 E:T ratio in medium with $500 \mathrm{U} / \mathrm{ml} \mathrm{rhIL-2}$ and $50 \mathrm{ng} / \mathrm{ml}$ rhIL-12. After $5 \mathrm{~d}$, K562 cells were added at a 10:1 E:T ratio. $6 \mathrm{~h}$ later, the NK cells were stained and analyzed by flow cytometry.

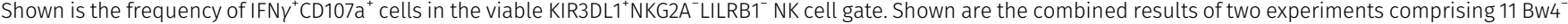
donors and $7 \mathrm{Bw} 4^{+}$donors. These results represent at least three replicate experiments. Shown are mean \pm SD and the results of a Sidak's multiple comparison test from a paired two-way ANOVA. ${ }^{*} P<0.05$, ${ }^{* *} P<0.01$, ${ }^{* * *} P<0.001$. (C) NK cells were isolated from PBMCs and co-cultured with 721.221 cells transfected to express either HLA-B $58: 01$ $\left(\mathrm{BW}^{+}\right)$or $\mathrm{B}^{*} 08: 01\left(\mathrm{Bw}^{-}\right)$. The cells were co-cultured at an 8:3 E:T ratio in medium with $500 \mathrm{U} / \mathrm{ml}$ rhlL-2. After $3 \mathrm{~d}$, the $\mathrm{K5} 62$ cells were added at a 10:1 E:T ratio. $6 \mathrm{~h} \mathrm{later}$, the NK cells were stained and analyzed by flow cytometry. The frequency of IFNY ${ }^{+}$cells in the KIR3DL1 ${ }^{+}$gate is shown. Shown are combined data from two experiments comprising six Bw $4^{-}$donors and nine BW $4^{+}$donors. These data represent at least three replicate experiments. Shown are mean \pm SD and the results of a Sidak's multiple comparison tests from a paired two-way ANOVA. ${ }^{*} P<0.05$. (D) 721.221 cells were transfected to express HLA-B*51:01 mutated to either abolish the Bw4 epitope (L82R,

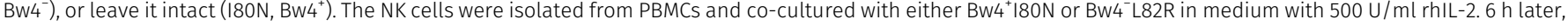
the NK cells were stained with antibodies and analyzed by flow cytometry. The frequency of IFNY ${ }^{+}$cells in the KIR3DL1 ${ }^{+}$gate is shown. Shown are mean \pm SD and the results of a $t$ test. ${ }^{*} P<0.01$. (E) NK cells were isolated from PBMC and co-cultured with 721.221 cells transfected to express HLA-B $51: 01$ with either the I80N (Bw4 $\left.{ }^{+}\right)$or L82R (Bw4 ${ }^{-}$) mutation. Cells were co-cultured at an 8:3 E:T ratio in medium with $500 \mathrm{U} / \mathrm{ml} \mathrm{rhIL-2}$. Additional isolated NK cells were cultured alone in medium with $500 \mathrm{U} / \mathrm{mL} \mathrm{rhIL}-2$ (No training). After $3 \mathrm{~d}$, K562 cells were added to co-cultures at a 10:1 E:T ratio, except for a portion of the NK cells cultured alone, which received only medium (No training or targets). $6 \mathrm{~h}$ later, NK cells were stained and analyzed by flow cytometry. The frequency of IFNY ${ }^{+}$cells in the KIR3DL1 ${ }^{+} N K G 2 A^{-}$gate is shown. Shown are the combined data comprising $20 \mathrm{BW} 4^{-}$donors and $8 \mathrm{BW} 4^{+}$donors from two experiments. These data represent at least three replicate experiments. Shown are mean \pm SD and the results of a Sidak's multiple comparison tests from a paired two-way ANOVA. NS $=$ not significant. ${ }^{*} P<0.05$.

Source data are available for this figure.

had no effect on the Bw4 epitope. Although functionally distinct, the L82R and I80N mutations mutants gave similar levels of cell surface expression (Fig S2B).

L82R and I80N mutants of $H L A-B^{\star} 15: 01$ were individually transfected into 721.221 cells. A 6-h co-culture of KIR3DL1+ ${ }^{+}$KK cells with $\mathrm{BW}^{+} \mid 80 \mathrm{~N}$ expressing target cells produced significantly less IFNy than KIR3DL1 ${ }^{+}$NK cells co-cultured with Bw4- L82R (Fig 5D). These results show that the $B w 4^{+} I 80 \mathrm{~N}$ mutant of $H L A-B^{*} 15$ : 01 engages KIRDL1 to inhibit NK cell cytolysis, whereas BW4- ${ }^{-}$82R does not.

After training with $\mathrm{Bw} 4^{+} 180 \mathrm{~N}, \mathrm{KIR} 3 \mathrm{DL} 1^{+} \mathrm{NK}$ cells from Bw4 $4^{-}$donors had a greater missing-self response than that achieved by KIR3DL1 ${ }^{+}$
NK cells trained with Bw4- L82R (Fig 5E). These results show that an intact Bw4 epitope is necessary for in vitro education of KIR3DL1 ${ }^{+} \mathrm{NK}$ cells.

\section{In vitro NK cell education is not abrogated by exposure to targets lacking HLA class I}

Educated mouse NK cells can lose their education if they are transplanted into mice lacking MHC class I (Wu \& Raulet, 1997; Joncker et al, 2010). Given this precedent, we tested whether the missing-self response of in vitro-educated KIR3DL1+ $1^{+}$KK cells is affected by exposure to human cells lacking HLA class I. 
We co-cultured one set of NK cells with BW4 ${ }^{-} \mathrm{BCL}$ and two sets of NK cells with $B w 4^{+} B C L$ in the presence of high IL-2. After $5 \mathrm{~d}$ of culture, NK cells were tested for a missing-self response to $\mathrm{K} 562$ cells, which express no HLA class I. NK cells co-cultured with $B w 4^{-} \mathrm{BCL}$ and one of the sets cultured with $\mathrm{Bw} 4^{+} \mathrm{BCL}$ were then assayed by flow cytometry. The other set of NK cells co-cultured with $B W 4^{+} \mathrm{BCL}$ remained in culture for another day, after which they were tested for a second time with $\mathrm{K} 562$ cells.

Among KIR3DL1 ${ }^{+} \mathrm{NK}$ cells from Bw4 $4^{-}$donors trained with $\mathrm{BW} 4^{+} \mathrm{BCL}$, the missing-self response during the second testing phase was not significantly lower than that observed during the first testing phase (Fig 6A). These data show that the missing-self response does not decline after a single exposure to $\mathrm{HLA}^{-}$target cells.

We next tested whether in vitro education is retained after multiple rounds of exposure to target cells lacking HLA class I. Isolated NK cells from $\mathrm{Bw} 4^{-}$donors were co-cultured with $\mathrm{Bw} 4^{-} \mathrm{BCL}$ and $\mathrm{BW} 4^{+} \mathrm{BCL}$ in the presence of high IL-2. After $5 \mathrm{~d}$ of training, NK cells were subjected to three rounds of testing with $\mathrm{K} 562$ cells, with $1 \mathrm{~d}$ of rest between each round. Of the KIR3DL1 ${ }^{+} \mathrm{NK}$ cells trained with $\mathrm{Bw} 4^{+} \mathrm{BCL}$ in the third round of testing, $27.2 \% \pm 3.8 \%$ of them produced IFNY in response to K562 cells (Fig 6B). This response was significantly higher than the $24.3 \% \pm 3.3 \%$ achieved by KIR3DL1 ${ }^{+} \mathrm{NK}$ cells trained with $\mathrm{Bw4} 4^{-} \mathrm{BCL}$ (Fig $6 \mathrm{~B}$ ). These data show that in vitro education of human NK cells can be retained after multiple rounds of exposure to target cells lacking HLA class I.

In general, education by $\mathrm{BW} 4^{+} \mathrm{BCL}$ produced a $33 \%$ increase in the frequency of IFN ${ }^{+} \mathrm{KIR} \mathrm{DL} 1^{+} \mathrm{NK}$ cells, as assessed in the first testing phase (Table 1). Thus, the 13\% increase observed after the third testing phase (Fig 6B) indicates that the effects of in vitro education
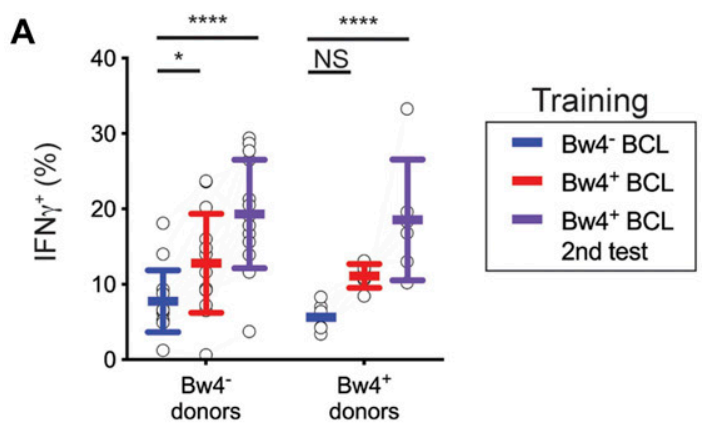

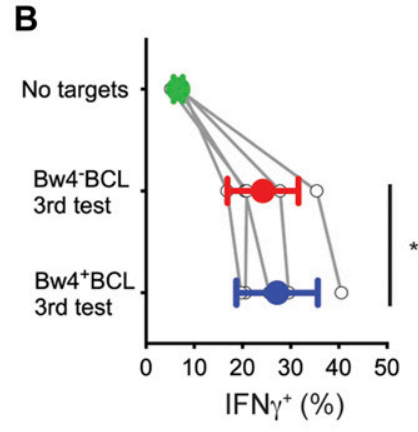

D

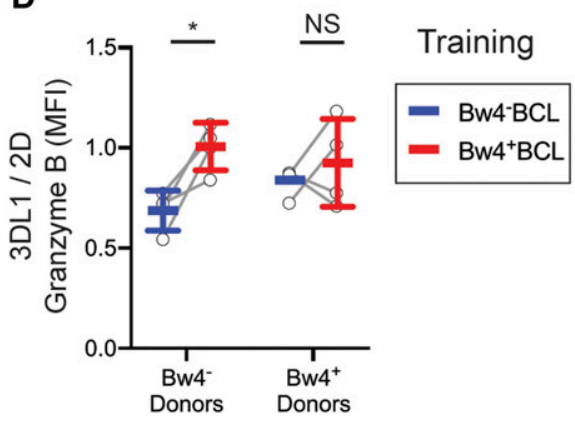

E

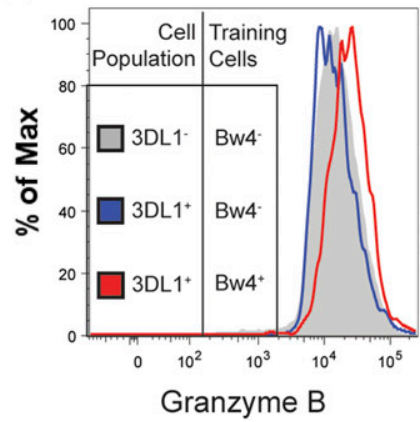

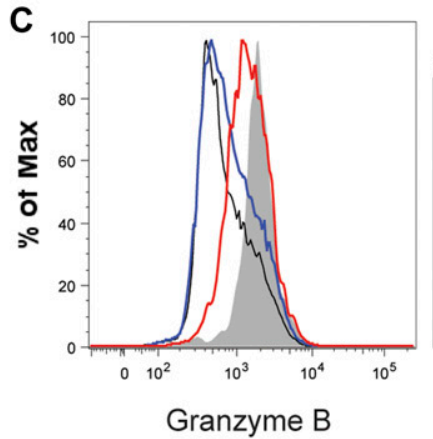

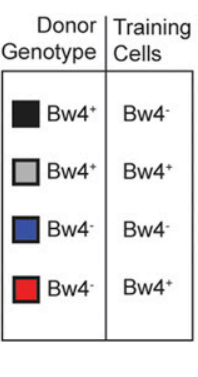

$\mathbf{F}$

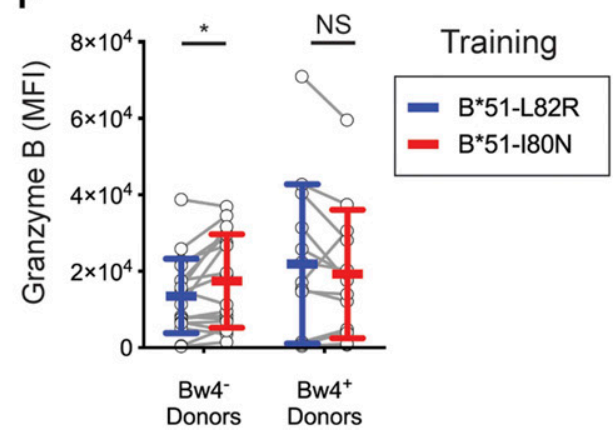

Figure 6. Training NK cells from $\mathrm{Bw}^{-}$donors with $\mathrm{Bw} 4^{+} \mathrm{BCL}$ improves their missing-self response to multiple rounds of $\mathrm{HLA}^{-}$cells, and increases their expression of granzyme B.

(A) NK cells were isolated from the PBMCs of $13 \mathrm{Bw}^{-}$donors and six Bw4+ donors. Two replicate groups of NK cells were then co-cultured with $\mathrm{Bw} 4^{+} \mathrm{BCL}$ and one group with Bw4- BCL, at an 8:3 E:T ratio in medium with $500 \mathrm{U} / \mathrm{ml}$ rhIL-2. After 5 d, K562 cells were added at a 10:1 E:T ratio (first testing). $6 \mathrm{~h}$ later, NK cells from co-cultures with Bw4- BCL and one of the $\mathrm{BW} 4^{+} \mathrm{BCL}$ co-cultures were stained and analyzed by flow cytometry. The other Bw $4^{+} \mathrm{BCL}$ co-culture was rested for $24 \mathrm{~h}$, after which more $\mathrm{K} 562 \mathrm{cells}$ were added at a 10:1 E:T ratio (second testing). $6 \mathrm{~h}$ later, NK cells were stained and analyzed by flow cytometry. The frequency of IFNY ${ }^{+}$cells in the viable KIR3DL1+NKG2A'LILRB1- NK cell gate is shown. These data represent at least three replicate experiments. Shown are mean \pm SD and the results of a Sidak's multiple comparison tests from a paired two-way ANOVA. ${ }^{*} P<0.05$, ${ }^{* * * *} P<0.0001$. (B) NK cells were isolated from the PBMCs of five Bw4 ${ }^{-}$donors and co-cultured with either Bw4 ${ }^{*} \mathrm{BCL}$ or Bw4 ${ }^{-} \mathrm{BCL}$ at an 8:3 $\mathrm{E}: \mathrm{T}$ ratio in medium with 500 $\mathrm{U} / \mathrm{ml}$ rhIL-2 (day 1). On days 5, 7, and 9, K562 cells were added at a 10:1 E:T ratio in medium with 500 U/ml rhIL-2. 6 h after adding K562 cells on day 9, NK cells were stained and analyzed by flow cytometry. The frequency of IFNY ${ }^{+}$cells in the viable KIR3DL1 ${ }^{+} N K G 2 A^{-}$LILRB1 ${ }^{-}$NK cell gate is shown. Shown are mean $\pm S D$ and the results of a paired $t$ test. ${ }^{*} P<$ 0.05. (C, D) NK cells were isolated from the PBMCs of four BW4 $4^{-}$donors and four BW $4^{+}$donors. NK cells were then co-cultured with either BW $4^{+} \mathrm{BCL}$ or BW4 ${ }^{-} \mathrm{BCL}$ at an 8:3 E:T ratio in medium with $500 \mathrm{U} / \mathrm{ml}$ rhIL-2. After $5 \mathrm{~d}$, $\mathrm{K} 562$ cells were added at a 10:1 E:T ratio, in medium with $500 \mathrm{U} / \mathrm{mL}$ rhIL-2. Two days later, the NK cells were stained and analyzed by flow cytometry. (C) Shown is a histogram of granzyme B expression of cells in the viable KIR3DL1+NKG2A- LILRB1- NK cell gate, obtained from concatenated flow cytometry data files for all eight donors. (D) Shown is the ratio between the granzyme B MFI for cells in the KIR3DL1 ${ }^{+} N K G 2 A^{-}$LILRB1 ${ }^{-}$NK cell gate and the cells in the KIR2D ${ }^{+}$KIR3DL1 ${ }^{-} N K G 2 A^{-}$LILRB1 ${ }^{-} N K$ cell gate. Shown are mean $\pm S D$ and the results of a Sidak's multiple comparison tests from a paired two-way ANOVA. ${ }^{*}<<0.05$. (E, F) NK cells were isolated from PBMCs and co-cultured with 721.221 cells transfected to express HLA-B*51:01 with either the I80N (BW4 ${ }^{+}$) or L82R (Bw4- ) mutation. The cells were co-cultured at an 8:3 E:T ratio in medium with $500 \mathrm{U} / \mathrm{ml}$ rhIL-2. After $5 \mathrm{~d}$, K562 cells were added at a 10:1 E:T ratio. After 2 more days, NK cells were stained and analyzed by flow cytometry.

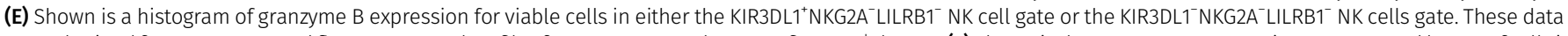
were obtained from concatenated flow cytometry data files from seven Bw4 ${ }^{-}$donors to five BW $4^{+}$donors. (F) Shown is the granzyme B expression as measured by MFI of cells in the viable KIR3DL1+NKG2A- LILRB1 ${ }^{-}$NK cell gate. These data were obtained from $18 \mathrm{BW}^{-}$donors to $13 \mathrm{Bw} 4^{+}$donors from three replicate experiments. Shown are mean \pm SD and the results of a Sidak's multiple comparison tests from a paired two-way ANOVA. NS $=$ not significant. ${ }^{*} P<0.05$.

Source data are available for this figure. 
decline if KIR3DL1 ${ }^{+}$NK cells have repeated encounters with HLA class I negative target cells.

\section{NK cells educated in vitro increase their intracellular granzyme B}

A distinguishing phenotype of educated NK cells is an increased amount of lysosomal granzyme B compared with uneducated NK cells (Goodridge et al, 2019). In contrast, we found no difference in lysosomal granzyme $\mathrm{B}$, when KIR3DL1+ $\mathrm{NK}$ cells from Bw4 ${ }^{-}$donors were trained with $\mathrm{Bw} 4^{+} \mathrm{BCL}$ or $\mathrm{Bw} 4^{-} \mathrm{BCL}$ (Fig S2D).

This result suggests that acquisition of granzyme $B$ by in vitro educated $\mathrm{KIR} \mathrm{DLL} 1^{+} \mathrm{NK}$ cells requires further differentiation. We examined if $\mathrm{KIR} \mathrm{DL} 1^{+} \mathrm{NK}$ cells increase their granzyme $\mathrm{B}$ after training, testing, and a period of rest in which they are incubated undisturbed. The NK cells were trained with either $B w 4^{+} B C L$ or $\mathrm{BW} 4^{-} \mathrm{BCL}$ for $5 \mathrm{~d}$, then tested with $\mathrm{K} 562$ cells and rested for $2 \mathrm{~d}$ in the presence of high IL-2. The KIR3DL1 ${ }^{+} \mathrm{NK}$ cells from Bw4- had increased granzyme B (MFI of 1734) compared with KIR3DL1+ ${ }^{+}$KK cells educated by Bw4-BCL (MFI of 1099) (Fig 6C).

Our study included only donors having similar levels of NK cell education mediated by the interactions of HLA-C with KIR2D (see the Materials and Methods section). We, therefore, hypothesized that in vitro education with Bw4 should increase the granzyme B in KIR3DL1 ${ }^{+} \mathrm{NK}$ cells relative to KIR2D ${ }^{+} \mathrm{NK}$ cells. The KIR3DL1/KIR2D ratio of granzyme B, as assessed by MFI, was $1.0 \pm 0.1 \mathrm{MFI}$ for NK cells from $B w 4^{-}$donors educated by $\mathrm{Bw} 4^{+} \mathrm{BCL}$ (Fig 6D). This was a significant increase over the $0.69 \pm 0.1$ ratio of NK cells trained with $\mathrm{Bw} 4^{-} \mathrm{BCL}$ (Fig 6D).

We next determined whether NK cells educated by a BW $4^{+} 221$ cell line would also develop more granzyme B. NK cells were cocultured with either Bw4 ${ }^{+} 180 \mathrm{~N}$ or Bw4- $4^{-} 82 \mathrm{R}$ cells. After $3 \mathrm{~d}, \mathrm{~K} 562$ cells were added at a 10:1 E:T ratio, and then NK cells were rested for 2 more days. Among the KIR3DL1 ${ }^{+} \mathrm{NK}$ cells from Bw4- donors, those that were educated by $B w 4^{+} \mid 80 \mathrm{~N}$ cells had a mean granzyme B MFI of $17,500 \pm 2,900$ (Fig $6 \mathrm{E}$ and $F$ ). This was significantly above the mean level $(13,500 \pm 2,300)$ of NK cells educated by Bw4- ${ }^{-}$L82R cells (Fig 6E and $F$ ).

In combination, these data indicate that in vitro education with Bw4 increases the homeostatic level of intracellular granzyme B, giving a phenotype like that of NK cells educated in vivo. This phenotype was only observed when initial education was followed by further stimulation and a period of rest.

\section{A synthetic mediator of NK cell education}

To test whether viable target cells are required to educate NK cells in vitro, we made synthetic targets displaying both HLA class I and ligands for activating NK cell receptors. First, streptavidin-coated paramagnetic beads were coated with two biotinylated monoclonal antibodies; one specific for CD2, and the other specific for DNAM1. The resulting anti-CD2-DNAM1 beads were then co-cultured with NK cells in medium with high IL-2. This culture enables the beads to bind and extract HLA class I from NK cell surfaces. After $48 \mathrm{~h}$, antiCD2-DNAM1 beads were isolated from the co-culture with a magnet. Beads were tested for bound HLA class I using FITC-labeled W6/32 antibody and were examined by light and fluorescence microscopy. Negative control beads were not cultured with NK cells.
The beads were distinguished from cells and cellular debris using light microscopy (Fig 7A). No auto-fluorescence was detected on unstained beads in the FITC channel (Fig 7A, first column). Among beads stained with FITC-W6/32, no fluorescence was detected on beads that were not cultured without NK cells (Fig 7A, second column). Anti-CD2-DNAM1 beads that were co-cultured with NK cells stained with fluorescent FITC-W6/32 (Fig 7A, third column). This indicates that HLA class I from NK cells was deposited on the beads during co-culture. The fluorescent signal was not diminished upon repeated washing and centrifugation of the beads (Fig 7A, fourth column). Anti-CD2-DNAM1 beads that have been co-cultured for $48 \mathrm{~h}$ with isolated NK cells are subsequently termed as reverse trogocytosis (RT) beads because the process by which they acquire HLA class I is like RT (Carlin et al, 2001).

To determine if one or both activation ligands on the anti-CD2DNAM 1 beads are necessary for RT, we made beads coated with only one of the anti-ligand antibodies. We then co-cultured isolated NK cells with anti-CD2 beads, anti-DNAM1 beads, or anti-CD2-DNAM1 beads in high IL-2 medium. A further control was a culture of antiCD2-DNAM1 beads without NK cells. After $48 \mathrm{~h}$, we magnetically isolated the beads from their respective co-cultures, stained them with W6/32, and analyzed them by flow cytometry. Anti-CD2 beads had a W6/32 MFI of 1831, which was higher than the 1086 W6/32 MFI of anti-CD2-DNAM1 beads (Fig 7B). RT-anti-DNAM1 beads had a W6/ $32 \mathrm{MFI}$ of 65 , an amount comparable with the MFI of beads cultured without NK cells, which was 30 (Fig 7B). This pattern indicates that the observed RT is mediated solely by the interaction between antiCD2 antibody and CD2.

\section{Beads coated with Bw4 ${ }^{+} \mathrm{HLA}-\mathrm{B}$ mediate in vitro NK cell education}

Anti-CD2-DNAM1 beads were incubated with NK cells derived from two donors. One donor had two copies of $B W 4^{+} H L A-B\left(H L A-B^{*} 51\right.$ and $\left.-B^{\star} 57\right)$, and the other donor lacked Bw4 (HLA-B*08 and $\left.-B^{*} 62\right)$. This provided $B W 4^{+} R T$ and $B W 4^{-} R T$ beads, respectively. The presence of BW $4^{+} \mathrm{HLA}-\mathrm{B}$ was confirmed on BW $4^{+} \mathrm{RT}$ beads using a Bw4-specific antibody (Fig S2E).

To determine if beads coated with HLA-B deposited by RT were sufficient to educate NK cells in vitro, isolated NK cells were cocultured with either the BW $4^{+} R T$ beads or the Bw $4^{-} R T$ beads for $5 \mathrm{~d}$ in medium with high IL-2. On day 5 , the medium was replaced, and co-cultures continued for another $2 \mathrm{~d}$. On day 7, NK cells were separated magnetically from beads and then co-cultured with K562 cells. KIR3DL1+NKG2A- NK cells were then assayed for IFNY expression.

On average, $45.6 \% \pm 18.5 \%$ of KIR3DL1 ${ }^{+} N K G 2 A^{-}$NK cells educated by $B W 4^{+} R T$ beads produced IFNy. This was significantly more than the $38.4 \% \pm 14.9 \%$ achieved by the NK cells co-cultured with Bw4 ${ }^{-} \mathrm{RT}$ beads (Fig 7C). This result shows that Bw $4^{+} \mathrm{RT}$ beads display the ligands necessary for some degree of in vitro NK cell education.

\section{Discussion}

This investigation demonstrates that education of mature peripheral KIR3DL1 ${ }^{+}$NK cells is feasible through in vitro interactions of KIR3DL1 
A

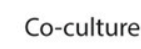

TRANSMITTED

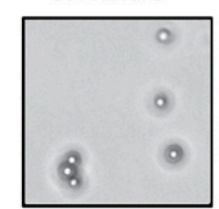

FLUORESCENT

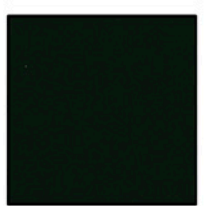

UNSTAINED
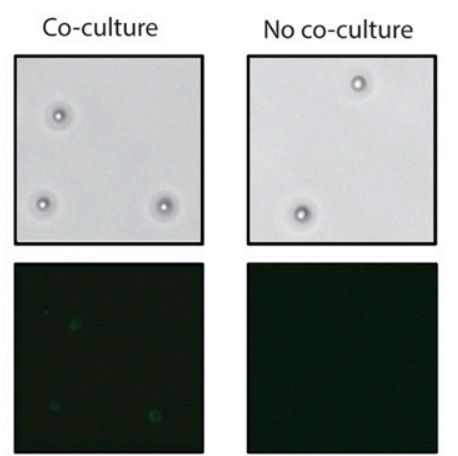

W6/32
Co-culture, isolation \& wash
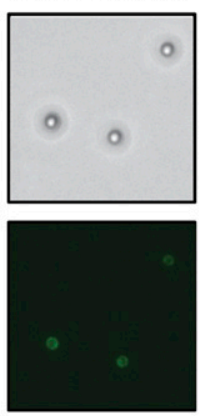

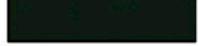

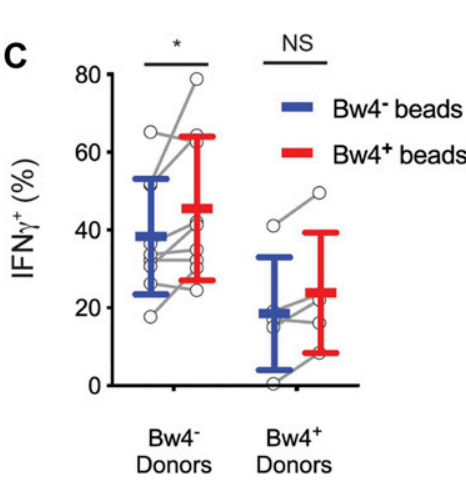

Figure 7. Synthetic beads displaying $B w 4^{+} H L A-B$ are sufficient to educate KIR3DL1 ${ }^{+}$NK cells in vitro.

(A) Biotinylated antibodies against CD2 and DNAM1 were bound to streptavidin-coated paramagnetic beads and co-cultured with NK cells isolated from PBMC for $2 \mathrm{~d}$ in medium with $500 \mathrm{U} / \mathrm{ml}$ rhlL-2. The beads were separated with a magnet, stained with anti-HLA class I, and analyzed by light and fluorescent microscopy. (B) NK cells were co-cultured for $2 \mathrm{~d}$ with paramagnetic beads coated with either anti-DNAM1, anti-CD2, or both anti-DNAM1 and antiCD2 antibodies. Co-cultures occurred in medium with $500 \mathrm{U} / \mathrm{ml}$ rhIL-2. Beads were isolated with a magnet, stained with anti-HLA class I and Alexa Fluor 700-labeled streptavidin, and analyzed by flow cytometry. Shown is the HLA signal of particles in the streptavidin ${ }^{+}$gate, which excludes all cells. Representative of at least three replicate experiments. (c) Two sets of reversetrogocytosed beads were constructed by co-culturing beads coated with anti-DNAM1 and anti-CD2 antibodies with NK cells from either $\mathrm{BW}_{4^{+}}$or $\mathrm{Bw} 4^{-}$donors. This produced beads coated in NK cell-derived membranes

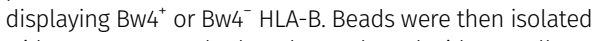
with a magnet, washed, and co-cultured with NK cells isolated from either $\mathrm{BW}_{4^{+}}$or $\mathrm{Bw} 4^{-}$donors. Co-cultures occurred in medium with $500 \mathrm{U} / \mathrm{ml}$ rhIL-2. After $7 \mathrm{~d}$, NK cells were separated from the beads with a magnet and combined with $\mathrm{K} 562$ cells at a 10:1 E:T ratio. $6 \mathrm{~h}$ later, the NK cells were stained with antibodies and analyzed by flow cytometry. Shown is combined data comprising nine $\mathrm{Bw}^{-}$donors and five $\mathrm{Bw}^{+}$donors from three replicate experiments. Shown are mean \pm SD and the results of a Sidak's multiple comparison tests from a paired two-way ANOVA. NS = not significant. ${ }^{*} P<0.05$. Source data are available for this figure. with $\mathrm{BW} 4^{+} \mathrm{HLA}-\mathrm{B}$. As predicted by studies of in vivo education (Yawata et al, 2006), in vitro education of KIR3DL1 ${ }^{+}$NK cells in our model requires the presence of an intact and accessible Bw4 epitope (Carr et al, 2005) and varied in magnitude according to the strength and number of KIR3DL1-HLA-B bonds (Yawata et al, 2006; Kim et al, 2008; Boudreau et al, 2016).

Although HLA-B has a half-life of about $12 \mathrm{~h}$ on the cell surface (Yarzabek et al, 2018), blocking HLA-B on BCL training cells at the outset of a 5 - $d$ training period abrogated in vitro education. This implies that the signals needed for in vitro education occur early in the training phase. In developing the training protocol, we found that the timing of training was dependent on the training cell line used and that inconsistent results were obtained if NK cells were trained for periods of only 24 or $48 \mathrm{~h}$. These observations, therefore, imply that the signaling necessary for in vitro education occurs at the outset of training and is followed by several days of maturation. That maturation is required for NK cell education is also supported by our observation that increased granzyme B levels, a phenotype associated with in vivo education, are only seen on NK cells from Bw4- donors after $5 \mathrm{~d}$ of training and $2 \mathrm{~d}$ of rest.

Throughout our study, we intentionally chose HLA-B alleles that bind strongly to KIR3DL1 for use in our Bw4 ${ }^{+}$training cells or beads. In most conditions, this resulted in improvements in NK cells from $\mathrm{Bw} 4^{-}$donors as well as those from $\mathrm{Bw}^{+}$donors, which already had achieved some degree of in vivo education through Bw4. The possibility of improving NK cells that have already experienced in vivo education greatly increases the number of human genotypes that could benefit from immunotherapy based on autologous in vitro NK cell education.

One potential issue with therapeutic applications of in vitro NK cell education is that such education is unlikely to be permanent. Educated mouse NK cells are de-educated when placed in an MHC ${ }^{-}$mouse (Wu \& Raulet, 1997; Joncker et al, 2010), suggesting that in vitro education would also be reversed in human NK cell immunotherapies. Likewise, in our experiments, in vivo education between $\mathrm{Bw}^{+}$and $\mathrm{Bw}^{-}$donors was not evident after training with $B w 4^{-}$cells. This suggests that in vivo education declines after exposure to Bw4- targets. In contrast, we also report the encouraging observation that in vitro NK cell education mediated by KIR3DL1 is sustained after more than one exposure to HLA- cells, supporting a model in which human NK cell education is plastic, but perhaps more easily gained than lost.

Opinions differ on whether, and under what circumstances, inflammatory cytokines can compensate for a lack of NK cell education (Juelke et al, 2009; Fauriat et al, 2010; Wagner et al, 2017). Although additional rhIL-2 increased the production of IFNy in our experiments, the effect of education on degranulation declined in medium with rhIL-2 and no other cytokines. Adding rhIL-12 during in vitro NK cell education reversed this situation, allowing education to be detected by degranulation but not IFNY production alone. These points outline a model in which NK cells educated in homeostatic or mildly stimulatory conditions support cytokine production, whereas those educated in more inflammatory conditions support degranulation. 
A potential weakness of our experimental design is that culturing NK cells for several days with cytokines induces a variety of transcriptional and metabolic changes that could confound the detection of NK cell education. Such changes include lysosomal biogenesis (Goodridge et al, 2019) and alterations in metabolism via the mTOR pathway (Marcais et al, 2017; Almutairi et al, 2019). Induction of these cellular programs also likely contributes to donorspecific variation of cell cultures.

Our experiments have not identified the co-factors that are sufficient for NK cell education. However, $\mathrm{BW}^{+}{ }^{+}$training consistently improved the missing-self response of NK cells by $\sim 30 \%$, regardless of whether $\mathrm{BCL}$ or 721.221 cells were used for training. This observation suggests that, apart from activation receptor ligands and KIR ligands, other co-factors are either ubiquitous or unnecessary for NK cell education. By contrast, KIR3DL1+ NK cells educated in vivo generally outperform uneducated NK cells by more than 30\% (Elliott et al, 2010), implying that our training did not achieve the highest degree of NK cell education. As shown by our analysis of in vivo education, one reason for this discrepancy is likely the duration of cell culture.

More robust in vitro education might be achieved if NK cells can be educated in vitro under more homeostatic conditions. However, the extent to which the activation of NK cells is required for in vitro education remains to be defined. It cannot be the case that homeostatic interactions between NK cells count toward education to the same degree as interactions between NK cells and training targets. Otherwise, in vitro education would be unlikely to take place because NK cells outnumbered training cells throughout our experiments. Moreover, training in media with high IL-2 \& IL-12 resulted in the most robust signal of in vitro education. A more rigorous study of metabolic and activation signaling during NK cell training will be necessary to define the role each has on the process of in vitro education.

Another potential reason that in vitro education appeared less effective than in vivo education is that our analyses excluded many NK cells that expressed other classes of inhibitory receptors contributing to NK cell education, such as NKG2A and LILRB1 (Sullivan et al, 2008). Additional study using a variety of training cell lines and conditions will be necessary to optimize in vitro education, and will likely include education through multiple classes of inhibitory receptors.

One mechanistic interpretation of our data is that NK cells receiving inhibitory signaling during the training phase were able to conserve functionality for the testing phase. In this scenario, KIR3DL1 ${ }^{+} \mathrm{NK}$ cells in the $\mathrm{BW}^{-}$training condition became more activated during training than those in the $\mathrm{Bw}_{4}^{+}$condition, thus depleting cellular resources. Then, in the testing phase, NK cells trained with $\mathrm{Bw}^{+}$had more resources available to respond to missing-self. Such an interpretation fits with the disarming model of NK cell education, in which a lack of inhibitory signaling erodes NK cell functionality over time (Raulet \& Vance, 2006).

A possible contradiction of this model is that NK cells cultured alone should conserve the most resources. Yet, untrained NK cells in our experiments did not outperform NK cells trained by Bw4. However, because of the extensive reprogramming induced by target interaction, it is unrealistic to make direct comparisons between trained and untrained NK cells. Therefore, the disarming model remains one reasonable interpretation of our data.
The $\mathrm{CD}^{-} 8^{-} \mathrm{CD} 2$ bond has low affinity (Davis et al, 1998) but is required for the formation of membrane nanotubes between NK cells and targets (Comerci et al, 2012). This may explain why NK cell membranes are disrupted and left behind after contact with beads displaying anti-CD2. RT beads introduce a novel tool, not only for the study of NK cell education but also for studies involving HLA presentation. For instance, by first infecting NK cells and then coculturing them with beads, RT beads displaying HLA with pathogenspecific epitopes could be easily isolated.

\section{Materials and Methods}

\section{Target cell lines}

B lymphoblastoid cell lines (BCLs) were generated by combining $10^{7}$ PBMCs with the B95.8 strain of EBV, as described previously (Neitzel, 1986). BCLs were cultured in RPMI-1640 medium (Corning) containing 10\% FBS (Corning), 2 mM L-glutamine (Thermo Fisher Scientific), and $100 \mathrm{U} / \mathrm{ml}$ of penicillin and streptomycin (Thermo Fisher Scientific). This medium is hereafter called RPMI10\%-C.

Both BCL cell lines were homozygous for the C1 epitope of HLA-C, and lack the $A 3 / 11$ epitope of HLA-A. Thus, both BCLs express the $C 1$ epitope recognized by KIR2DL2 and KIR2DL3. In contrast, one $\mathrm{BCL}$ (Bw4 ${ }^{+} \mathrm{BCL}$ ) expressed the Bw4 epitope recognized by KIR3DL1, whereas the other $\mathrm{BCL}\left(\mathrm{BW} 4^{-} \mathrm{BCL}\right)$ does not. $\mathrm{BW} 4^{+} \mathrm{BCL}$ expressed $\mathrm{HLA}-\mathrm{B}^{\star} 51$ and $B^{\star} 57$, whereas $B w 4^{-} B C L$ expressed $H L A-B^{*} 08$ and $B^{\star} 62$.

721.221 transfectant cell lines were generated and maintained as described previously (Sanjanwala et al, 2008). In summary, plasmid expression vector pEF6-V5-His containing either $B * 5801$, $B * 0801$, or mutant $B * 5101$ cDNA was transfected into 221 cells by electroporation using Gene Pulser (Bio-Rad Laboratories). Afterward, 221 cells were cultured and maintained under selection in RPMI10\% with $5 \mu \mathrm{g} / \mathrm{ml}$ blasticidin (Invitrogen).

Site-specific mutation of HLA-B ${ }^{\star} 5101$ was performed as previously described (Ho et al, 1989; Sanjanwala et al, 2008). In summary, two oligonucleotide primers (Stanford PAN Facility) were designed to encode the desired mutation and to bind to the area surrounding the mutation site, one each for the 5' and 3' DNA strands. Each of those primers was used in a separate PCR to amplify either the CDNA sequence upstream or downstream from the mutation site. The resulting amplicons were then purified and combined in a second $P C R$ reaction, thereby forming the full-length mutant CDNA. In one mutant, residue 82 of $B * 51: 01$ was mutated to encode arginine in-

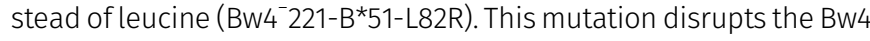
epitope, thereby preventing the binding of KIR3DL1, as described previously (Sanjanwala et al, 2008). In another mutant, residue 80 of $B * 51: 01$ was mutated to encode asparagine instead of isoleucine (Bw4 ${ }^{+} 221-B^{\star} 51-180 N$ ). This alteration does not disrupt the Bw4 epitope.

\section{Blood acquisition and processing}

Leukoreduction and separation chambers obtained from healthy, CMV-free donors were purchased from the Stanford Blood Center. PBMCs from the leukoreduction and separation chambers were isolated on a Ficoll-Paque gradient (GE Healthcare) and then suspended 
in FBS (Corning) containing 10\% DMSO (EMD Millipore) at $10^{7} / \mathrm{ml}$. Aliquots were frozen at $-80^{\circ} \mathrm{C}$ for several days using a Mr. Frosty device (Thermo Fisher Scientific) and then stored in liquid nitrogen.

Before experiments, frozen aliquots of PBMCs were thawed at $37^{\circ} \mathrm{C}$ in a water bath and suspended in $10 \mathrm{ml}$ of $37^{\circ} \mathrm{C} \mathrm{RPMI} 10 \%-\mathrm{C}$. The cells were then spun at $300 \mathrm{~g}$ for $10 \mathrm{~min}$, resuspended in $2 \mathrm{ml}$ of RPMI $10 \%-C$ with $100 \mathrm{U} / \mathrm{ml}$ recombinant human IL-2 (rhIL-2), and transferred to 12 -well plates at $10^{7}$ cells per well. The cells were kept in a $37^{\circ} \mathrm{C}$ incubator with $5 \% \mathrm{CO}_{2}$ for $>12 \mathrm{~h}$ before any further manipulation. The IL-2 was obtained from Dr. Maurice Gately (Hoffmann-La Roche Inc.), through the National Institutes of Health AIDS Reagent Program, Division of AIDS, National Institute of Allergy and Infectious Diseases, National Institutes of Health.

\section{HLA and KIR genotyping}

HLA and KIR were genotyped as described previously (Norman et al, 2016). In summary, DNA was extracted from whole blood using the QIAamp DNA Blood Mini Kit (QIAGEN) following the manufacturer's instructions. Genomic DNA fragments representing complete HLA-A, $H L A-B, H L A-C$, and KIR genes were isolated using oligonucleotide probes and sequenced using an Illumina MiSeq machine with v3 technology (Illumina Inc.), as previously described (Norman et al, 2016).

\section{Donor selection}

$\mathrm{Bw}^{-}{ }^{-}$individuals were defined as having no Bw4 epitope on either $\mathrm{HLA}-\mathrm{A}$ or HLA-B. BW $4^{+}$donors were defined by the presence of BW 4 on HLA-B. Donors were selected to be homozygous for the C1 epitope of HLA-C.

\section{NK isolation}

NK cells were isolated from PBMCs using the Untouched NK Isolation Kit with LS columns (Miltenyi Biotec), as described previously (Pugh et al, 2018). In this procedure, all PBMCs except NK cells were bound to paramagnetic beads by antibodies. This mixture was then passed through a column in the presence of a magnet, which trapped all PBMCs, except NK cells, in the column. The NK cell-enriched flowthrough was then washed and suspended in RPMI10\%-C.

\section{Etoposide treatment of training lines}

Training lines in all experiments were subjected to etoposide treatment before co-culture with NK cells. $10^{6} \mathrm{BCL}$ or 221 cells in RPMI10\%-C were transferred to a six-well plate at $10 \mathrm{ml} /$ well. VP-16 was added to the media. The final concentration of VP16 etoposide was determined empirically for each training line to halt division, generally $125-250 \mathrm{mM}$. The cells were then incubated at $37^{\circ} \mathrm{C}$ in $5 \%$ $\mathrm{CO}_{2}$ for $4 \mathrm{~h}$. The cells were then spun at $300 \mathrm{~g}$ and washed with $25 \mathrm{ml}$ RPMI10\%-C three times before being used in NK cell co-cultures.

\section{In vitro education using B cell lines}

200,000 NK cells from each donor were co-cultured with VP16treated BCL target cells at an 8:3 E:T ratio in flat-bottom 96-well plates. The cells were co-cultured in X-vivo 15 medium (Lonza) with $10 \%$ FBS (10\% X-vivo). The medium included either $100 \mathrm{U} / \mathrm{ml} \mathrm{rhIL}-2$, $500 \mathrm{U} / \mathrm{ml} \mathrm{rhIL-2,} \mathrm{or} 500 \mathrm{U} / \mathrm{ml}$ rhlL-2 and $50 \mathrm{ng} / \mathrm{ml}$ rhIL-12 (eBioscience) Thermo Fisher Scientific). The cells were co-cultured at $37^{\circ} \mathrm{C}$ in $5 \% \mathrm{CO}_{2}$ for $5 \mathrm{~d}$, without disturbance. NK cells were then assayed for their response to $\mathrm{K} 562$ cells.

\section{In vitro education using 221 transfectant lines}

200,000 isolated NK cells were co-cultured with VP16-treated 221 cells at a 1:2 T:E ratio. The cells were co-cultured in 96-well flatbottom plates in $10 \%$ X-vivo medium with $500 \mathrm{U} / \mathrm{ml} \mathrm{rhIL-2}$ at $37^{\circ} \mathrm{C}$ in $5 \% \mathrm{CO}_{2}$. The medium was checked daily for discoloration and changed as needed, at most every $24 \mathrm{~h}$. To change the medium, cocultured cells were transferred to round-bottom 96-well plates, pelleted at $\sim 700 \mathrm{~g}$, resuspended in fresh medium, and then returned to flat-bottom plates. After $3 \mathrm{~d}$, the NK cells were assayed for their response to $\mathrm{K} 562$ cells.

\section{Activation beads and RT}

Activation beads were constructed using the NK Cell Expansion Kit, as directed by the manufacturer (Miltenyi Biotec). In summary, biotinylated antibodies were bound to paramagnetic beads coated with streptavidin. Antibodies comprised anti-CD2 (Miltenyi Biotec) and anti-DNAM1 (Miltenyi Biotec), either in combination or alone.

RT was accomplished by combining activation beads with 200,000 isolated NK cells at a ratio of 1:2 in 96-well flat-bottom plates in 200 $\mu \mathrm{l} 10 \%$ X-vivo with $500 \mathrm{U} / \mathrm{ml}$ rhIL-2. $48 \mathrm{~h}$ later, each co-culture was agitated by repeated pipetting and then transferred to a $1.2-\mathrm{ml}$ microtiter tube (Thermo Fisher Scientific) containing $100 \mu \mathrm{l}$ of X-vivo 15 medium. To harvest RT beads, the microtiter tube was suspended in the open groove of a horizontally positioned MidiMACS separator magnet (Miltenyi Biotec). After $5 \mathrm{~min}$, the entire volume of the medium was gently extracted from the bottom of the microtiter tube, leaving the beads held by the magnet on the inner sides of the tube. The beads were immediately resuspended by removing them from the magnetic field and adding RPMI-1640. This magnetic isolation process was repeated to further purify the bead fraction. Last, suspensions of beads were transferred to a $1.5-\mathrm{ml}$ tube and stored at $4^{\circ} \mathrm{C}$ for several days before experimentation.

\section{In vitro education using RT-beads}

Beads were constructed, subjected to RT, and isolated as described above. 200,000 NK cells were combined with RT beads in a flat-bottom 96-well plate at a 5:1 cell : bead ratio in 10\% X-vivo medium with $500 \mathrm{U} / \mathrm{ml}$ rhIL-2. Co-cultures were incubated undisturbed for $5 \mathrm{~d}$ at $37^{\circ} \mathrm{C}$ in $5 \% \mathrm{CO}_{2}$. On day 5 , co-cultures were transferred to a 96 -well round-bottom plate, pelleted by centrifugation at $300 \mathrm{~g}$, suspended in fresh medium and returned to flatbottom plates. Co-cultures were then incubated for 2 more days. On day 7, co-cultures were transferred to a microtiter tube and NK cells were separated from beads using a MidiMACS magnet, as described above. Isolated NK cells were then assayed for their response to K562 cells. 


\section{Functional assays}

After in vitro education, NK cells were transferred to a round-bottom 96-well plate, pelleted by centrifugation at $700 \mathrm{~g}$, and suspended in $100 \mu \mathrm{l}$ of $10 \%$ X-vivo media with $500 \mathrm{U} / \mathrm{ml} \mathrm{rhlL}-2$ and $5 \mu \mathrm{g} / \mathrm{ml}$ Brefeldin A (Sigma-Aldrich). For degranulation assays, each well contained $2 \mu \mathrm{l}$ of anti-CD107a antibody (eBioH4A3; eBioscience/Thermo Fisher Scientific). Target cells were then added to each well at a 1:10 T:E ratio. Co-cultures were incubated for $6 \mathrm{~h}$ at $37^{\circ} \mathrm{C}$ in $5 \% \mathrm{CO}_{2}$. Co-cultures were then pelleted by centrifugation at $4^{\circ} \mathrm{C}$, washed twice with icecold magnetic assisted cell separation (MACS) buffer, and stained with antibodies to detect cell surface proteins.

\section{$\mathrm{F}\left(\mathrm{ab}^{\prime}\right)_{2}$ production}

W6/32 antibody was purified from the spent medium of cultured W6/32 hybridoma cells as described previously (Parham et al, 1979). $\mathrm{F}\left(\mathrm{ab} \mathrm{b}^{\prime}\right)_{2}$ were prepared from W6/32 antibody using the Pierce $\mathrm{F}\left(\mathrm{ab} \mathrm{b}^{\prime}\right)^{2}$ Preparation Kit (Thermo Fisher Scientific), following the manufacturer's protocol. In summary, 1-mg batches of W6/32 antibody were added to spin columns containing equilibrated immobilized pepsin. Fc was then digested by pepsin for $1 \mathrm{~h}$ at $37^{\circ} \mathrm{C}$. Undigested IgG was removed by binding to Protein $A$. Batches of purified $F\left(a b^{\prime}\right)_{2}$ were tested for their ability to block whole W6/32 antibody (Fig S2A).

\section{CMV infection}

Human CMV strain VHL/E was a kind gift from James Waldman (Waldman et al, 1989). MRC-5 cells were acquired from American Type Culture Collection and cultured in Eagles Minimum Essential Medium (EMEM) (Gibco) with 10\% FBS (Corning). MRC-5 cells were infected overnight in serum-free EMEM, then cultured in 10\% EMEM for $4 \mathrm{~d}$ postinfection before being assayed for Bw4, or used as testing targets for in vitro education assays.

\section{Antibodies}

Seven fluorescently conjugated monoclonal antibodies specific for cell surface proteins were used to analyze NK cells. These comprised antiCD19 (HIB19; eBioscience/Thermo Fisher Scientific), anti-CD-107a (eBioH4A3; eBioscience/Thermo Fisher Scientific), anti-KIR3DL1 (DX9; BioLegend), anti-NKG2A (REA110; Miltenyi Biotec), anti-LILRB1 (GHI/75; BioLegend), anti-panKIR2D (NKVFS1; Miltneyi), and anti-DNAM1 (11A8; BioLegend). Four fluorescently conjugated monoclonal antibodies were used to detect the following intracellular markers: anti-IFNy (45.B3; BioLegend), anti-BrdU (51-23619L; BD Pharmingen), anti-granzyme B (QA16A02; BioLegend), and anti-granzyme B (GB11; BD Bioscience).

\section{Cell staining, fixation, and flow cytometry}

Cultures containing NK cells were stained in U-bottom, 96-well plates with antibodies specific for cell surface proteins, as described previously (Pugh et al, 2018). The staining concentration of each antibody was determined empirically, ranging from 1 to $3 \mu \mathrm{l}$ per test. The cells were stained in a total volume of $50 \mu \mathrm{l}$ PBS with $0.5 \%$ bovine serum albumin (Sigma-Aldrich) and 2 mM EDTA (MACS buffer). The cells were stained in the dark at $4^{\circ} \mathrm{C}$ for a period of between 0.5 and $12 \mathrm{~h}$. The stained cells were then washed with 200 $\mu \mathrm{l}$ PBS and pelleted by centrifugation at $\sim 700 \mathrm{~g}$ for $3 \mathrm{~min}$ at $4^{\circ} \mathrm{C}$. This washing step was repeated twice. During subsequent steps, the reagents and plates were kept on ice.

To identify and exclude dead cells from analysis, cultures were then stained with a 500-fold dilution of Live/Dead Yellow (Thermo Fisher Scientific) in PBS. The cells were stained in a total volume of $50 \mu \mathrm{l}$ for $30 \mathrm{~min}$ at $4^{\circ} \mathrm{C}$. The cells were washed twice with MACS buffer and then treated with $100 \mu$ l of fixative solution (BD Cytofix; $\mathrm{BD}$ Biosciences). After $10 \mathrm{~min}$ of incubation at $4^{\circ} \mathrm{C}, 100 \mu \mathrm{l}$ of perm buffer ( $1 \times$ BD Perm; BD Biosciences) were added to each well, to permeabilize the cells. The cells were then washed twice with $200 \mu \mathrm{l}$ of perm buffer. To ensure the permeability of intracellular compartments, the cells were incubated with $200 \mu \mathrm{l}$ of perm buffer containing $10 \%$ DMSO, at $4^{\circ} \mathrm{C}$ for $20 \mathrm{~min}$, followed by three more washes in perm buffer. The cells were then treated again with $100 \mu$ l fixative solution to ensure the fixation of intracellular compartments, followed by two more washes with perm buffer. For BrDU detection, DNA was digested by incubating cells with $30 \mu \mathrm{g} / \mathrm{ml}$ DNase I (Sigma-Aldrich) in perm buffer at room temperature in the dark for 30 min. To detect BrDU or intracellular proteins, the cells were stained with antibodies in $50 \mu \mathrm{l}$ of perm buffer for $30 \mathrm{~min}$ at $4^{\circ} \mathrm{C}$. The cells were washed twice with perm buffer and once with MACS buffer before analysis.

The cells were analyzed using an LSR II flow cytometer (BD Biosciences) at the Stanford Shared FACS Facility. Sphero midrange Rainbow Fluorescent beads (Spherotech) were used to calibrate and verify the performance of all channels before each data collection session. The same cytometer was used when comparing samples from the same experiment collected on different days. Data points appearing in paired comparisons were collected on the same cytometer in the same day without interruption. Data were analyzed using FlowJo Ver. 9.7.6 (FlowJo, LLC). Concatenation was performed using Flowjo Ver. 10.6.1.

\section{B\&EF calculation}

Binding scores were generated by color quantifying the heat map dataset of (Boudreau et al, 2016) using Adobe Photoshop CS6 Version 16 (Adobe Inc.). Binding quantities were normalized on a continuous scale from 1 to 10. Donors for whom all KIR-HLA-B combinations were represented in the binding data were selected. Each of the four possible HLA-B-KIR bonds when training with the Bw4 ${ }^{+}$cell line was calculated for each donor. Scores for the four bonds were then averaged, resulting in a single overall binding score for each donor. The overall binding score for each donor was then multiplied by 1,000 and multiplied by the MFI of KIR3DL1 for that donor. The KIR3DL1 MFI was recorded after NK cell isolation but before training or any co-culture.

\section{Microscopy}

Microscope images were captured using an EVOS FL microscope (Life Technologies), using a 20× LPlanFL lens. Fluorescent images were captured using an EVOS LED Cube GFP (F1013-1410-314) and EVOS software (revision 21773). Paired transmission and fluorescent images were taken with the same positioning and cropped to display the same cell grouping using Adobe Photoshop CS6 version 13 (Adobe Inc.). 


\section{Statistics}

Data were assessed for statistical significance using Prism Ver. 6 (GraphPad Software). Generally, paired samples from the same donor were compared with a paired two-way ANOVA.

\section{Supplementary Information}

Supplementary Information is available at https://doi.org/10.26508/lsa. 201900434.

\section{Acknowledgements}

We thank Amir Horowitz, Emily Wroblewski, Hugo Hilton, and Katherine Walwyn-Brown for technical and scientific input. We also thank the Stanford Shared FACS Facility for flow cytometry and sorting support. This work was supported by a grant from the National Institutes of Health, Al017892, to P Parham.

\section{Author Contributions}

J Pugh: conceptualization, data curation, formal analysis, investigation, project administration, and writing-original draft, review, and editing.

N Nemat-Gorgani: data curation and formal analysis.

Z Djaoud: investigation.

LA Guethlein: data curation and formal analysis.

PJ Norman: data curation and formal analysis.

P Parham: supervision, project administration, and writing-original draft, review, and editing.

\section{Conflict of Interest Statement}

The authors declare that they have no conflict of interest.

\section{References}

Almutairi SM, Ali AK, He W, Yang DS, Ghorbani P, Wang L, Fullerton MD, Lee SH (2019) Interleukin-18 up-regulates amino acid transporters and facilitates amino acid-induced mTORC1 activation in natural killer cells. I Biol Chem 294: 4644-4655. doi:10.1074/jbc.ra118.005892

Ameres S, Mautner J, Schlott F, Neuenhahn M, Busch DH, Plachter B, Moosmann A (2013) Presentation of an immunodominant immediateearly CD8+ T cell epitope resists human cytomegalovirus immunoevasion. PLoS Pathog 9: e1003383. doi:10.1371/ journal.ppat.1003383

Andersson S, Fauriat C, Malmberg JA, Ljunggren HG, Malmberg KJ (2009) KIR acquisition probabilities are independent of self-HLA class I ligands and increase with cellular KIR expression. Blood 114: 95-104. doi:10.1182/blood-2008-10-184549

Anfossi N, Andre P, Guia S, Falk CS, Roetynck S, Stewart CA, Breso V, Frassati C, Reviron D, Middleton D, et al (2006) Human NK cell education by inhibitory receptors for MHC class I. Immunity 25: 331-342. doi:10.1016/ j.immuni.2006.06.013

Babic M, Pyzik M, Zafirova B, Mitrovic M, Butorac V, Lanier LL, Krmpotic A, Vidal SM, Jonjic S (2010) Cytomegalovirus immunoevasin reveals the physiological role of "missing self" recognition in natural killer cell dependent virus control in vivo. J Exp Med 207: 2663-2673. doi:10.1084/ jem.20100921

Boegel S, Lower M, Bukur T, Sorn P, Castle JC, Sahin U (2018) HLA and proteasome expression body map. BMC Med Genomics 11: 36. doi:10.1186/s12920-018-0354-X

Boudreau JE, Mulrooney TJ, Le Luduec JB, Barker E, Hsu KC (2016) KIR3DL1 and HLA-B density and binding calibrate NK education and response to HIV. J Immunol 196: 3398-3410. doi:10.4049/jimmunol.1502469

Bukur J, Jasinski S, Seliger B (2012) The role of classical and non-classical HLA class I antigens in human tumors. Semin Cancer Biol 22: 350-358. doi:10.1016/j.semcancer.2012.03.003

Carlin LM, Eleme K, McCann FE, Davis DM (2001) Intercellular transfer and supramolecular organization of human leukocyte antigen $C$ at inhibitory natural killer cell immune synapses. J Exp Med 194: 1507-1517. doi:10.1084/jem.194.10.1507

Carr WH, Pando MJ, Parham P (2005) KIR3DL1 polymorphisms that affect NK cell inhibition by HLA-Bw4 ligand. J Immunol 175: 5222-5229. doi:10.4049/jimmunol.175.8.5222

Colonna M, Samaridis J (1995) Cloning of immunoglobulin-superfamily members associated with HLA-C and HLA-B recognition by human natural killer cells. Science 268: 405-408. doi:10.1126/science.7716543

Comerci CJ, Mace EM, Banerjee PP, Orange JS (2012) CD2 promotes human natural killer cell membrane nanotube formation. PLoS One 7: e47664. doi:10.1371/journal.pone.0047664

Crux NB, Elahi S (2017) Human leukocyte antigen (HLA) and immune regulation: How do classical and non-classical HLA alleles modulate immune response to human immunodeficiency virus and hepatitis $C$ virus infections? Front Immunol 8: 832. doi:10.3389/fimmu.2017.00832

Davis SJ, Ikemizu S, Wild MK, van der Merwe PA (1998) CD2 and the nature of protein interactions mediating cell-cell recognition. Immunol Rev 163 : 217-236. doi:10.1111/j.1600-065x.1998.tb01199.x

Eguizabal C, Zenarruzabeitia O, Monge J, Santos S, Vesga MA, Maruri N, Arrieta A, Rinon M, Tamayo-Orbegozo E, Amo L, et al (2014) Natural killer cells for cancer immunotherapy: Pluripotent stem cells-derived NK cells as an immunotherapeutic perspective. Front Immunol 5: 439. doi:10.3389/ fimmu.2014.00439

Elliott JM, Wahle JA, Yokoyama WM (2010) MHC class I-deficient natural killer cells acquire a licensed phenotype after transfer into an MHC class Isufficient environment. J Exp Med 207: 2073-2079. doi:10.1084/ jem.20100986

Fauriat C, Ivarsson MA, Ljunggren HG, Malmberg KJ, Michaelsson J (2010) Education of human natural killer cells by activating killer cell immunoglobulin-like receptors. Blood 115: 1166-1174. doi:10.1182/blood-2009-09-245746

Goodridge JP, Jacobs B, Saetersmoen ML, Clement D, Hammer Q, Clancy T, Skarpen E, Brech A, Landskron J, Grimm C, et al (2019) Remodeling of secretory lysosomes during education tunes functional potential in NK cells. Nat Commun 10: 514. doi:10.1038/s41467-019-08384-x

Gras Navarro A, Bjorklund AT, Chekenya M (2015) Therapeutic potential and challenges of natural killer cells in treatment of solid tumors. Front Immunol 6: 202. doi:10.3389/fimmu.2015.00202

Greenberg AH, Playfair JH (1974) Spontaneously arising cytotoxicity to the P815-Y mastocytoma in NZB mice. Clin Exp Immunol 16: 99-109.

Guethlein LA, Norman PJ, Hilton HG, Parham P (2015) Co-evolution of MHC class I and variable NK cell receptors in placental mammals. Immunol Rev 267: 259-282. doi:10.1111/imr.12326

Ho SN, Hunt HD, Horton RM, Pullen JK, Pease LR (1989) Site-directed mutagenesis by overlap extension using the polymerase chain reaction. Gene 77: 51-59. doi:10.1016/0378-1119(89)90358-2

Joncker NT, Shifrin N, Delebecque F, Raulet DH (2010) Mature natural killer cells reset their responsiveness when exposed to an altered MHC environment. J Exp Med 207: 2065-2072. doi:10.1084/jem.20100570 
Juelke K, Killig M, Thiel A, Dong J, Romagnani C (2009) Education of hyporesponsive NK cells by cytokines. Eur J Immunol 39: 2548-2555. doi:10.1002/eji.200939307

Karre K, Ljunggren HG, Piontek G, Kiessling R (1986) Selective rejection of H-2deficient lymphoma variants suggests alternative immune defence strategy. Nature 319: 675-678. doi:10.1038/319675a0

Kiessling R, Petranyi G, Karre K, Jondal M, Tracey D, Wigzell H (1976) Killer cells: A functional comparison between natural, immune T-cell and antibody-dependent in vitro systems. J Exp Med 143: 772-780. doi:10.1084/jem.143.4.772

Kim N, Kim HS (2018) Targeting checkpoint receptors and molecules for therapeutic modulation of natural killer cells. Front Immunol 9: 2041. doi:10.3389/fimmu.2018.02041

Kim S, Sunwoo JB, Yang L, Choi T, Song YJ, French AR, Vlahiotis A, Piccirillo JF, Cella M, Colonna M, et al (2008) HLA alleles determine differences in human natural killer cell responsiveness and potency. Proc Natl Acad Sci U S A 105: 3053-3058. doi:10.1073/pnas.0712229105

Lanier LL (2003) Natural killer cell receptor signaling. Curr Opin Immunol 15: 308-314. doi:10.1016/s0952-7915(03)00039-6

Marcais A, Marotel M, Degouve S, Koenig A, Fauteux-Daniel S, Drouillard A, Schlums H, Viel S, Besson L, Allatif O, et al (2017) High mTOR activity is a hallmark of reactive natural killer cells and amplifies early signaling through activating receptors. Elife 6: e26423. doi:10.7554/elife.26423

Michaelsson J, Teixeira de Matos C, Achour A, Lanier LL, Karre K, Soderstrom K (2002) A signal peptide derived from hsp60 binds HLA-E and interferes with CD94/NKG2A recognition. J Exp Med 196: 1403-1414. doi:10.1084/jem.20020797

Misra MK, Augusto DG, Martin GM, Nemat-Gorgani N, Sauter J, Hofmann JA, Traherne JA, Gonzalez-Quezada B, Gorodezky C, Bultitude WP, et al (2018) Report from the killer-cell immunoglobulin-like receptors (KIR) component of the 17th International HLA and Immunogenetics Workshop. Hum Immunol 79: 825-833. doi:10.1016/ j.humimm.2018.10.003

Moesta AK, Norman PJ, Yawata M, Yawata N, Gleimer M, Parham P (2008) Synergistic polymorphism at two positions distal to the ligandbinding site makes KIR2DL2 a stronger receptor for HLA-C than KIR2DL3. J Immunol 180: 3969-3979. doi:10.4049/jimmunol.180.6.3969

Neitzel H (1986) A routine method for the establishment of permanent growing lymphoblastoid cell lines. Hum Genet 73: 320-326. doi:10.1007/bf00279094

Norman PJ, Hollenbach JA, Nemat-Gorgani N, Marin WM, Norberg SJ, Ashouri E, Jayaraman J, Wroblewski EE, Trowsdale J, Rajalingam R, et al (2016) Defining KIR and HLA class I genotypes at highest resolution via highthroughput sequencing. Am J Hum Genet 99: 375-391. doi:10.1016/ j.ajhg.2016.06.023

Parham P, Barnstable CJ, Bodmer WF (1979) Use of a monoclonal antibody (W6/32) in structural studies of HLA-A,B,C, antigens. J Immunol 123: 342-349.

Parham P, Moffett A (2013) Variable NK cell receptors and their MHC class I ligands in immunity, reproduction and human evolution. Nat Rev Immunol 13: 133-144. doi:10.1038/nri3370

Pugh JL, Nemat-Gorgani N, Norman PJ, Guethlein LA, Parham P (2018) Human NK cells downregulate Zap70 and Syk in response to prolonged activation or DNA damage. J Immunol 200: 1146-1158. doi:10.4049/ jimmunol.1700542

Raulet DH, Vance RE (2006) Self-tolerance of natural killer cells. Nat Rev Immunol 6: 520-531. doi:10.1038/nri1863

Robinson J, Guethlein LA, Cereb N, Yang SY, Norman PJ, Marsh SGE, Parham P (2017) Distinguishing functional polymorphism from random variation in the sequences of $>10,000$ HLA-A, $-B$ and $-C$ alleles. PLoS Genet 13: e1006862. doi:10.1371/journal.pgen.1006862

Robinson J, Soormally AR, Hayhurst JD, Marsh SG (2016) The IPD-IMGT/HLA database: New developments in reporting HLA variation. Hum Immunol 77: 233-237. doi:10.1016/j.humimm.2016.01.020

Sanjanwala B, Draghi M, Norman PJ, Guethlein LA, Parham P (2008) Polymorphic sites away from the Bw4 epitope that affect interaction of Bw4+ HLA-B with KIR3DL1. J Immunol 181: 6293-6300. doi:10.4049/ jimmunol.181.9.6293

Schonberg K, Sribar M, Enczmann J, Fischer JC, Uhrberg M (2011) Analyses of HLA-C-specific KIR repertoires in donors with group $A$ and $B$ haplotypes suggest a ligand-instructed model of NK cell receptor acquisition. Blood 117: 98-107. doi:10.1182/blood-2010-03-273656

Seliger B, Maeurer MJ, Ferrone S (1997) TAP off-tumors on. Immunol Today 18: 292-299. doi:10.1016/s0167-5699(97)01052-9

Storkus WJ, Howell DN, Salter RD, Dawson JR, Cresswell P (1987) NK susceptibility varies inversely with target cell class I HLA antigen expression. J Immunol 138: 1657-1659.

Sullivan LC, Clements CS, Rossjohn J, Brooks AG (2008) The major histocompatibility complex class Ib molecule HLA-E at the interface between innate and adaptive immunity. Tissue Antigens 72: 415-424. doi:10.1111/j.1399-0039.2008.01138.x

Tabi Z, Moutaftsi M, Borysiewicz LK (2001) Human cytomegalovirus pp65- and immediate early 1 antigen-specific HLA class I-restricted cytotoxic T cell responses induced by cross-presentation of viral antigens. J Immunol 166: 5695-5703. doi:10.4049/jimmunol.166.9.5695

Toubi E, Vadasz Z (2019) Innate immune-responses and their role in driving autoimmunity. Autoimmun Rev 18: 306-311. doi:10.1016/ j.autrev.2018.10.005

Valiante NM, Phillips JH, Lanier LL, Parham P (1996) Killer cell inhibitory receptor recognition of human leukocyte antigen (HLA) class I blocks formation of a pp36/PLC-gamma signaling complex in human natural killer (NK) cells. J Exp Med 184: 2243-2250. doi:10.1084/jem.184.6.2243

Wagner JA, Berrien-Elliott MM, Rosario M, Leong JW, Jewell BA, Schappe T, Abdel-Latif S, Fehniger TA (2017) Cytokine-induced memory-like differentiation enhances unlicensed natural killer cell antileukemia and FcgammaRIIla-triggered responses. Biol Blood Marrow Transplant 23: 398-404. doi:10.1016/j.bbmt.2016.11.018

Waldman WJ, Sneddon JM, Stephens RE, Roberts WH (1989) Enhanced endothelial cytopathogenicity induced by a cytomegalovirus strain propagated in endothelial cells. J Med Virol 28: 223-230. doi:10.1002/ jmv.1890280405

Wu MF, Raulet DH (1997) Class I-deficient hemopoietic cells and nonhemopoietic cells dominantly induce unresponsiveness of natural killer cells to class I-deficient bone marrow cell grafts. Immunol 158: 1628-1633.

Yarzabek B, Zaitouna AJ, Olson E, Silva GN, Geng J, Geretz A, Thomas R, Krishnakumar S, Ramon DS, Raghavan M (2018) Variations in HLA-B cell surface expression, half-life and extracellular antigen receptivity. Elife 7: e34961. doi:10.7554/elife.34961

Yawata M, Yawata N, Draghi M, Little AM, Partheniou F, Parham P (2006) Roles for HLA and KIR polymorphisms in natural killer cell repertoire selection and modulation of effector function. J Exp Med 203: 633-645. doi:10.1084/jem.20051884

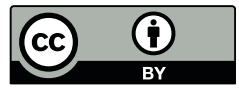

License: This article is available under a Creative Commons License (Attribution 4.0 International, as described at https://creativecommons.org/ licenses/by/4.0/). 